\title{
Improving the Fracture Toughness of Multi-Layered Commercial Pure Aluminum via Warm Accumulative Roll Bonding
}

\section{Ali Akhavan Attar}

Bu-Ali Sina University

Ali Alavi Nia ( $\square$ alavi1338@yahoo.com )

Bu-Ali Sina University

Yousef Mazaheri

Bu-Ali Sina University

Ehsan Ghassemali

School of Engineering, Jönköping University

\section{Research Article}

Keywords: Warm ARB, Fracture toughness, Tensile strength, SEM fractography, AA1050.

Posted Date: March 12th, 2021

DOl: https://doi.org/10.21203/rs.3.rs-283710/v1

License: (c) (i) This work is licensed under a Creative Commons Attribution 4.0 International License. Read Full License

Version of Record: A version of this preprint was published at The International Journal of Advanced Manufacturing Technology on July 21st, 2021. See the published version at https://doi.org/10.1007/s00170-021-07687-y. 


\title{
Improving the fracture toughness of multi-layered commercial pure
}

\section{aluminum via warm accumulative roll bonding}

\author{
Ali Akhavan Attar ${ }^{\text {a, }}$, Ali Alavi Nia ${ }^{\text {a," }}$, Yousef Mazaheri ${ }^{\text {b }}$, Ehsan Ghassemali ${ }^{\mathrm{c}}$ \\ a Department of Mechanical Engineering, Bu-Ali Sina University, Hamedan 65178-38695, Iran \\ b Department of Materials Engineering, Bu-Ali Sina University, Hamedan 65178-38695, Iran \\ ${ }^{\mathbf{c}}$ Department of Materials and Manufacturing, School of Engineering, Jönköping University, 55111 Jönköping, Sweden \\ * Corresponding author. at: Department of Mechanical Engineering, Faculty of Engineering, Bu-Ali Sina University, Hamedan 65178- \\ 38695, Iran.

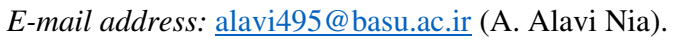

\begin{abstract}
In this study, the fracture toughness of the multi-layered commercial pure aluminum samples (AA1050) prepared by warm accumulative roll bonding (WARB) was investigated for the first time. Based on the ASTM E561 standard, the R-curve method was utilized to measure the plane stress fracture toughness. Compact tension (CT) samples were prepared from the sheets that were processed by different ARB cycles. Mechanical properties, microstructure, and fracture surfaces of the CT samples were studied by uniaxial tensile test, electron backscatter diffraction (EBSD), and scanning electron microscopy (SEM), respectively. By increasing the number of WARB cycles, fracture toughness increased; after five cycles, $78 \%$ enhancement was observed compared to the pre-processed state. A correlation was seen between the fracture toughness variations and ultimate tensile strength (UTS). WARB enhanced UTS up to 95\%, while the grain size showed a reduction from 35 to $1.8 \mu \mathrm{m}$. Measured fracture toughness values were compared with the room temperature ARB outcomes, and the effective parameters were analyzed.
\end{abstract}


Fractography results indicated that the presence of tiny cliffs and furrows and hollow under fatigue loading zones and shear ductile rupture in the Quasi-static tensile loading zone.

Keywords: Warm ARB, Fracture toughness, Tensile strength, SEM fractography, AA1050.

\section{Introduction}

Severe plastic deformation processes (SPD) have attracted the attention of researchers due to the extraordinary features and ultra-fine grain structure (UFG). In this regard, numerous studies have been conducted on various types of SPD, such as equal channel angular pressing (ECAP)[1,2], high-pressure torsion (HPT)[3], constrained groove pressing (CGP)[4], simple shear extrusion (SSE)[5], and accumulative roll bonding (ARB)[6-9].

Among these processes, ARB, which was developed by Saito et al. [10], rapidly found its place among researchers and industrialists. The fast and low-cost processing of ARB has introduced it as one of the best technique to produce metallic sheets with UFG structure. Numerous studies have addressed the mechanical properties and microstructural alterations of metals and different alloys such as aluminum, copper, nickel, steel, and titanium [11-13,7,14,15]. Qualitative and quantitative investigations indicated a decrease in the grain size as well as wide variations in the dislocation density and other microstructural parameters, an increase of strength and hardness, brittleness enhancement, and edge cracking in the prepared samples [16-18].

On the other hand, aluminum has always been focused on attention due to its unique properties and extensive applications. ARB-produced aluminum sheets have managed to reinforce these properties. Su et al. [19] conducted five cycles of ARB at room temperature on AA1050 sheets and compared their strength properties and microstructure with the ECAP-processed samples. Their results showed far higher strength of the ARB-produced specimens. Wang et al. [20] investigated the microstructure, texture, and mechanical properties of ARB-produced AA1060 
sheets at cryogenic temperatures. They repeated successive cycles in these samples that resulted in a significant increase in the tensile strength along with a dramatic decline in the elongation. In general, investigation on the fracture behavior of metals under SPD, along with the conventional strength and stiffness examination, can offer valuable information that can be used in their application in engineering structures [21]. Some of the studies in this regard indicated that the fracture toughness could exhibit various behaviors under SPD as it sometimes increased and sometimes decreased. For instance, the titanium sample prepared by the ECAP method showed lower fracture toughness compared to its pre-treated state [22], while the same process on AA7075 enhanced the fracture toughness [23].

So far, a limited number of studies have addressed the fracture toughness of the ARB-produced sheets from several alloys $[24,14,25,26]$. These studies have shown that the ARB process has a significant effect on the fracture toughness. Rahmatabadi et al. [24] exclusively examined the fracture toughness of room temperature ARB-produced AA1050 and proved that the plane stress fracture toughness could significantly increase by raising the number of the process cycles. After the five ARB cycles, the fracture toughness $142 \%$ increased. Despite the valuable results offered by the previous studies on the fracture toughness of ARB sheets, there is still some lack of information. For instance, providing the grain size or boundary misorientation would help in a deeper understanding of the fracture toughness variations. Besides, the grain size of initial samples was not reported before the ARB process, while a simultaneous comparison of fracture toughness and grain size in the first and last cycles can present valuable information about the relationship between the grain size and fracture toughness. Additionally, they tested CT samples by the tensile test with no fatigue pre-crack creation, whereas the test related to the fracture toughness measurement will offer more precise results by fatigue pre-crack creation $[27,28]$. In 
the previous studies, the ARB process was limited to room temperature, and they did not address the effect of elevated temperature.

In the current study, the effect of WARB on the fracture toughness of pure commercial aluminum was investigated for the first time. Moreover, it was tried to resolve the gaps in the previous studies. The ARB process was carried out in five cycles at elevated temperatures. Fracture properties, strength behavior, and microstructural evolutions of the samples were analyzed and compared before and after the different cycles using EBSD, plane stress fracture toughness test, fractography, tensile test, and atomic force microscopy (AFM).

\section{Experimental procedure}

\subsection{Materials and $A R B$ processing}

A commercial pure AA1050 alloy was utilized in this research. Pieces with dimensions of 250 $\mathrm{mm} \times 80 \mathrm{~mm} \times 2 \mathrm{~mm}$ were cut in a direction parallel to the sheet rolling direction. The asreceived strips were annealed at $380^{\circ} \mathrm{C}$ for 2 hours for homogenization.

Fig. 1 indicates the schematic of the ARB method. The following steps were completed for the surface preparation in this investigation. Initially, the specimens were cleaned. After that, a stainless steel brush with wires of $0.3 \mathrm{~mm}$ diameter was used to wire-brush them. Finally, an acetone bath was used to degrease the samples. No lubricant was utilized in the ARB procedure. Two strips were treated using a laboratory rolling mill with two rolls of $230 \mathrm{~mm}$ diameter. They stacked together by riveting their ends under a loading capacity of 20 tons and a rolling speed of $50 \mathrm{rpm}$. After cutting the rolled specimens sheets to two halves and cleaning their surfaces, the

specimens were stacked together again. The samples were heated in a furnace at $180{ }^{\circ} \mathrm{C}$, and 
afterwards, they were instantly roll-bonded under given conditions to create a proper bonding between strips. This process was repeated until five cycles with a $50 \%$ decrease at every cycle (total equivalent strain accumulated equals to 4$)$. The equivalent strain ( $\left.\varepsilon_{\text {eq }}\right)$ during the $\mathrm{ARB}$ procedure can be calculated as follows [10]:

$\varepsilon_{e q}=\frac{2}{\sqrt{3}} n \ln \frac{t_{0}}{t}=\frac{2}{\sqrt{3}} n \ln \frac{1}{1-r}$

where $t_{0}, t, r$, and $n$ indicate the initial thickness, the thickness after roll-bonding, the relative decrease in thickness per cycle, and the number of ARB cycles, respectively. The application of $50 \%$ decrease in every ARB cycle results in an equivalent strain of around 0.8 per cycle.

As-received annealed sample $(\mathrm{C} 0)$ and produced sheets from 1st (C1), 3rd (C3), and 5th ARB cycle (C5) were prepared to examine the microstructural and mechanical investigations.

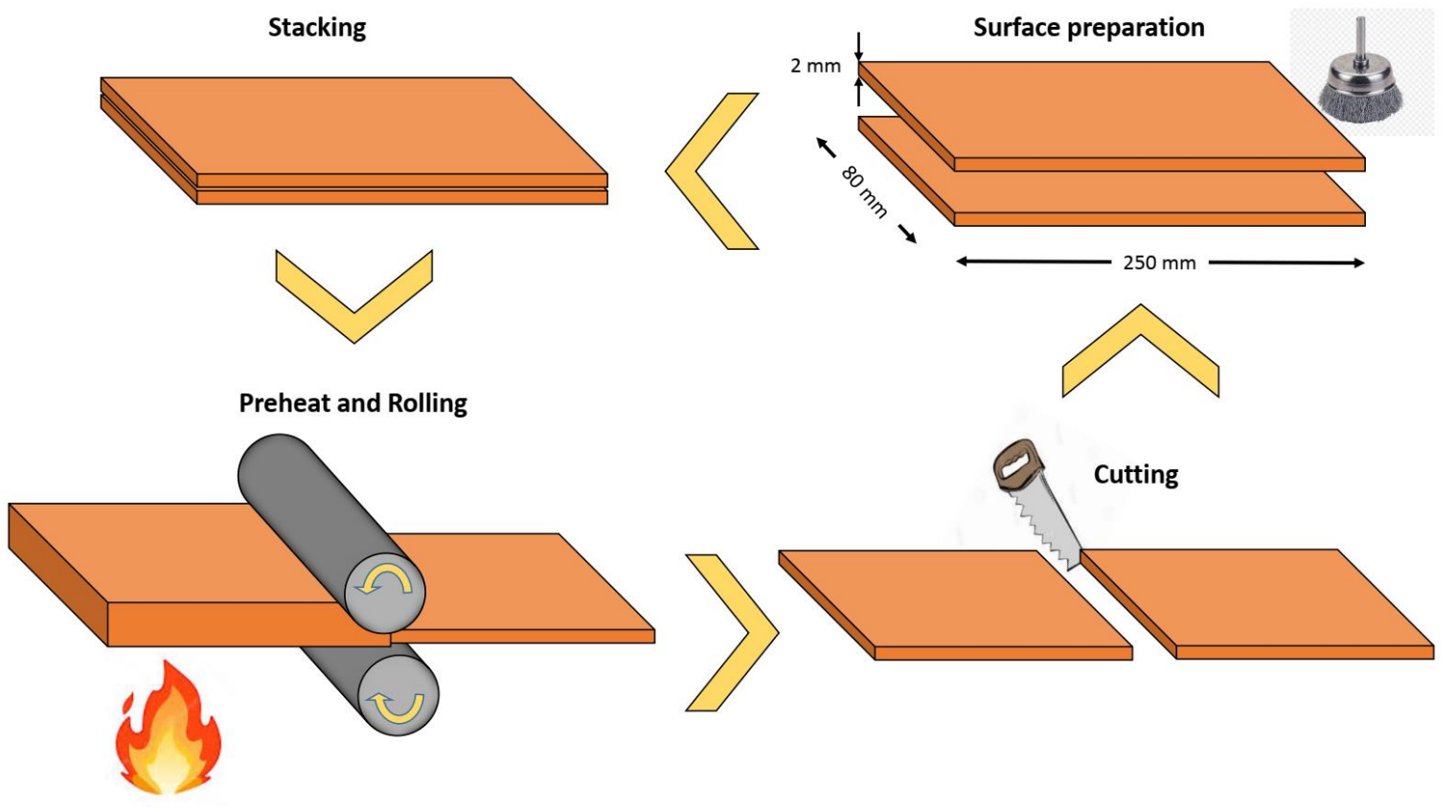

Fig. 1. Schematic design of the WARB procedure. 


\subsection{Microstructural and roughness characterizations}

The electron backscatter diffraction (EBSD) analysis was used to characterize the microstructure of the specimens in a field emission scanning electron microscope (FE-SEM, JEOL JSM7001F). Microstructural investigations were done on the perpendicular plane to both the rolling direction (RD) and normal direction (ND) along the transverse direction (TD). Following steps were performed for preparing the specimens suitable for the EBSD measurements. First, sandpaper was employed to polish the strips longitudinally normal to the transverse direction. Afterwards, a solution of $10 \% \mathrm{HClO}_{4}$ and $90 \% \mathrm{C}_{2} \mathrm{H}_{5} \mathrm{OH}$ were used to electro-polish the strips at $15 \mathrm{~V}$ for 15 $25 \mathrm{~s}$ at $-20^{\circ} \mathrm{C}$. EBSD investigations were done using an FE-SEM equipped with an EBSD detector using a step size of $0.5 \mu \mathrm{m}$ at the accelerating voltage of $15 \mathrm{KV}$. The EBSD results were analyzed using the OIM (TSL) software. The size of grains was measured using the linear intercept method.

To investigate the fracture surfaces, they were characterized using a scanning electron microscope (SEM, JEOL JSM840A) after the CT tests.

An atomic force microscope (AFM, ARA Research) was used to perform the surface roughness measurements. Silicon nitride was utilized as the microscope cantilever. The curvature radius of the tip was in the nanometer range.

\subsection{Mechanical properties evaluations}

For utilizing tensile tests, the ARB processed strips were cut and machined according to the ASTM E8 standard. The preparation of the samples was performed with caring to make the tensile direction parallel to the strips' rolling direction (RD). The gauge width and length of the tensile samples were $5 \pm 0.1$ and $15.5 \pm 0.1 \mathrm{~mm}$, respectively. The tests were conducted by a 
STM-50 tensile testing system having a fixed crosshead with a speed of $1 \mathrm{~mm} / \mathrm{min}$. Also, the difference between the gauge lengths before and after the test was used for determining the total elongation of all samples. Three tensile tests were performed for each sample to confirm the results' accuracy.

\subsection{Fracture toughness measurements}

For evaluating the capability of the replication of the fracture toughness results, plane stress fracture toughness tests were performed for three specimens after various ARB cycles and in the initial stage. ASTM-E561 standard was utilized to introduce standard compact tension (CT) specimens. A wire cut machine was employed to prepare the specimens and to make pre-cracks in the specimens. As shown in Fig. 2, the specimens were of dimensions $22.5 \mathrm{~mm} \times 21.6 \mathrm{~mm} \times 2$ $\mathrm{mm}$. A thin slit was induced in the specimen by machining. In addition, a $60^{\circ} \mathrm{v}$-notch was created. The notch machining was performed perpendicular to the loading axis and at the equal distance from the top and bottom edges of the specimen. The notch tip can initiate fatigue precrack. Consequently, the v-notch tip was further expanded up to $1.5 \mathrm{~mm}$. The wire-cut machining using a wire with a radius of $250 \mu \mathrm{m}$ was utilized to conduct this extension. Notably, the exclusively Mode I loading condition was applied to the CT type specimen. A tensile oscillation load of $20 \mathrm{~Hz}$ frequency was applied by Zwick/Roell machine to expand the pre-crack fatigue by at least $0.65 \mathrm{~mm}$ for achieving a finely sharp crack tip. In line with the ASTM-E561 standard, it was suggested that more than 5000 cycles should be applied to complete the finishing stage. 
The displacement control at a constant rate was utilized to perform all of the fracture tests. The experimental arrangement of the CT specimens can be observed in Fig.3. A moving head speed of $0.06 \mathrm{~mm} / \mathrm{s}$ was used to load the specimens quasi-statically .

(a)

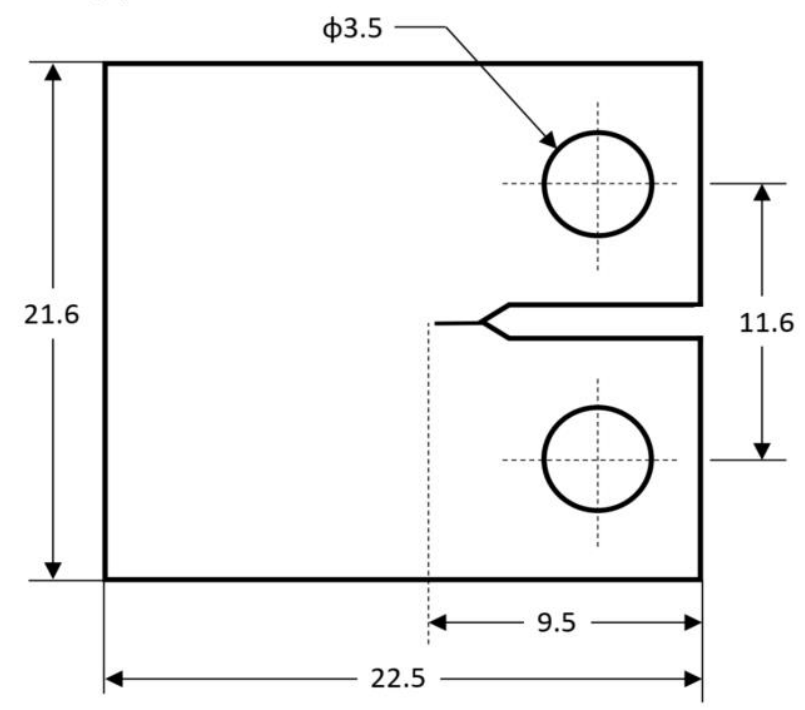

(b)

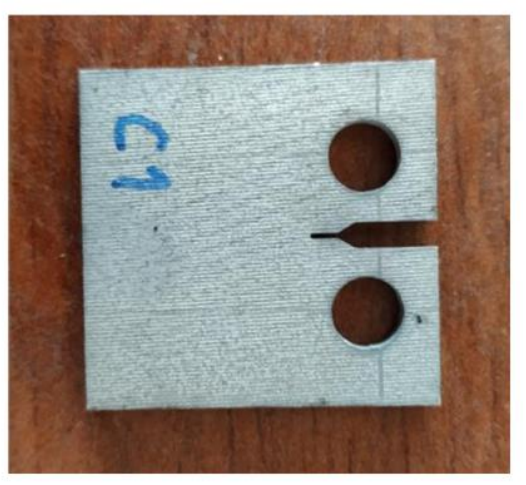

Fig. 2. (a) Dimensions of CT sample according to ASTM E561 standard (all dimensions in mm) and (b) one sample made by Wire-cut 


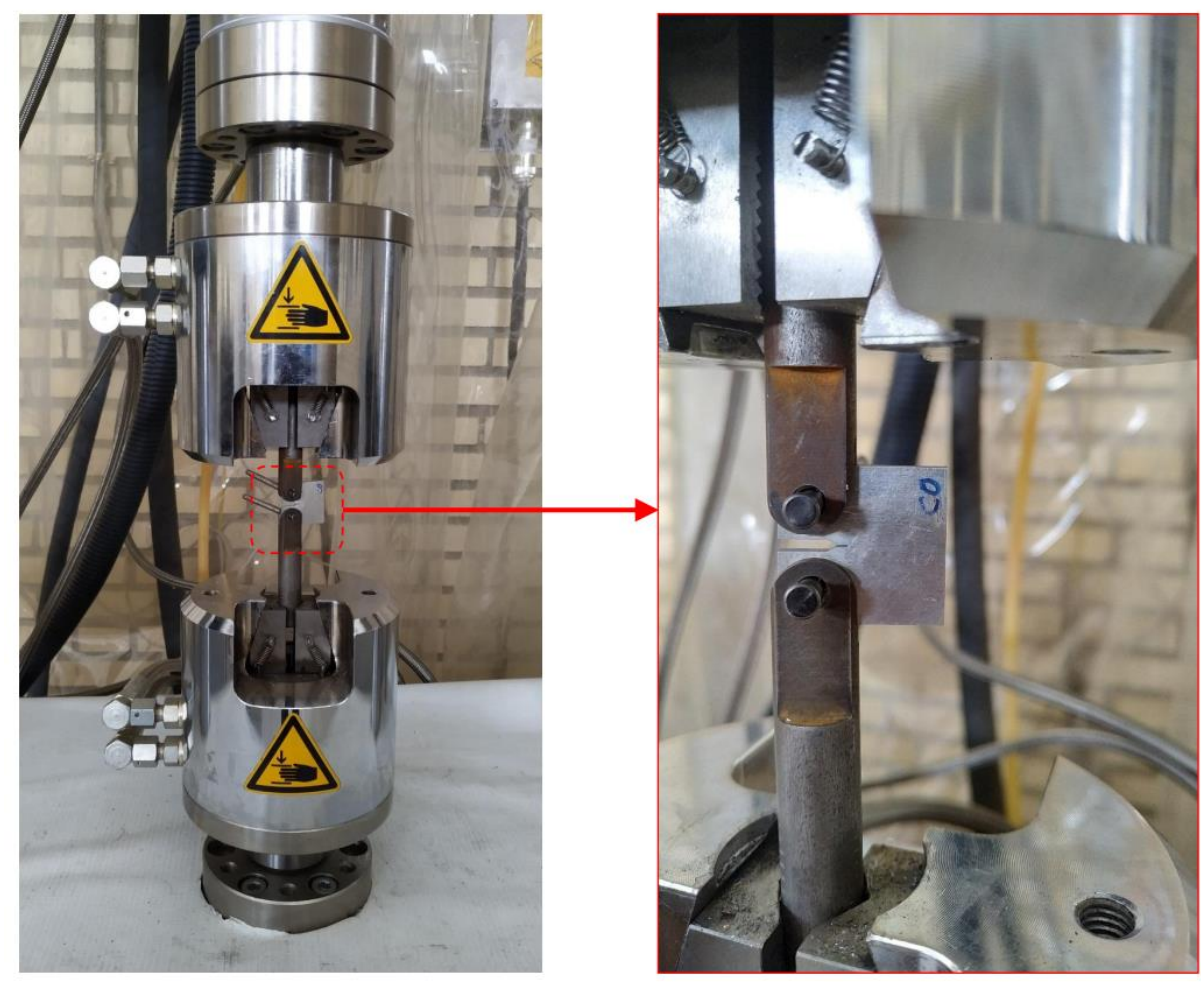

Fig. 3. Experimental setup of the CT test in Zwick/Roell machine.

\section{Results and discussion}

\subsection{Microstructural evaluations}

The EBSD analysis was executed at the thickness points representing the RDXND plane centers. The grain boundary maps (GB map), as well as RD inverse pole figure (IPF) maps are represented in Fig. 4.

In the GB maps, black lines show the high angle grain boundaries (HAGBs) with the misorientation angle greater than $15^{\circ}$, while red lines indicate low-angle grain boundaries (LAGBs) with the misorientation angle in the range of $2-15^{\circ}$. Boundaries were having angles smaller than $2^{\circ}$ were ignored for eliminating the inaccuracy of EBSD measurements [29]. 
As shown in Fig. 4, elongated initial grains (C0) subdivided by dislocation boundaries in most microstructures after different $\mathrm{ARB}$ passes $(\mathrm{C} 1, \mathrm{C} 3$, and $\mathrm{C5})$. The $\mathrm{GB}$ maps indicate that boundaries normally have low angle misorientations and a tendency for aligning in RD. In the IPF map, every point's color is related to a crystallographic direction corresponding to the RD of the ARB processed sheets consistent with the stereographic triangle legend.

Measured points which had confidence indexes (CI) smaller than 0.1 were removed before performing EBSD analysis. These points are represented with black color in the maps. As shown by Fig. 4, some samples have broad bands occupied by several black zones. These are the bonded interfaces.

Up to five cycles, the grain size decreased by increasing the number of ARB cycles. The annealing process led to recrystallization and creation of the equiaxed grains from deformed structures. The size of the annealed sample's grains was $35 \mu \mathrm{m}$ that reduced to $1.8 \mu \mathrm{m}$ after the five cycles due to the grain refinement in the ARB process.

C0

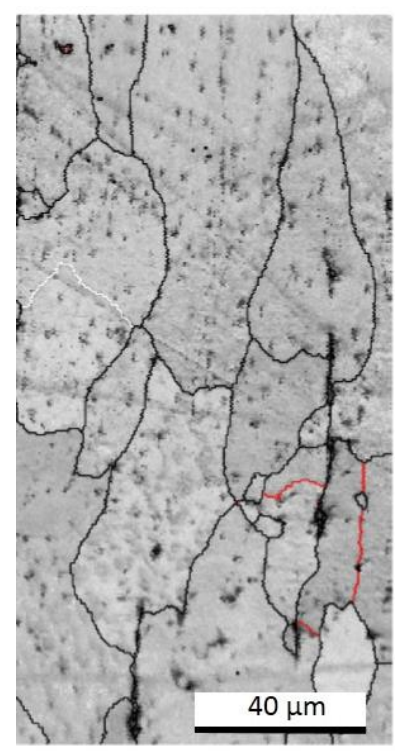

C1

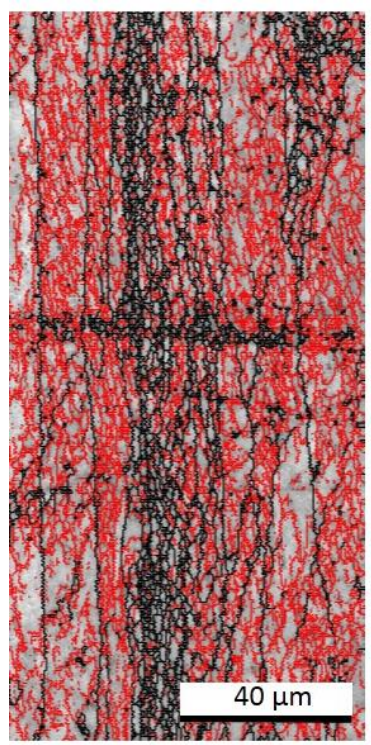

C3

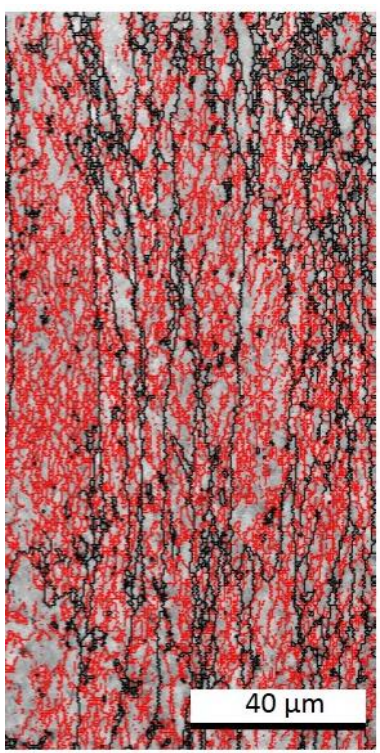

C5

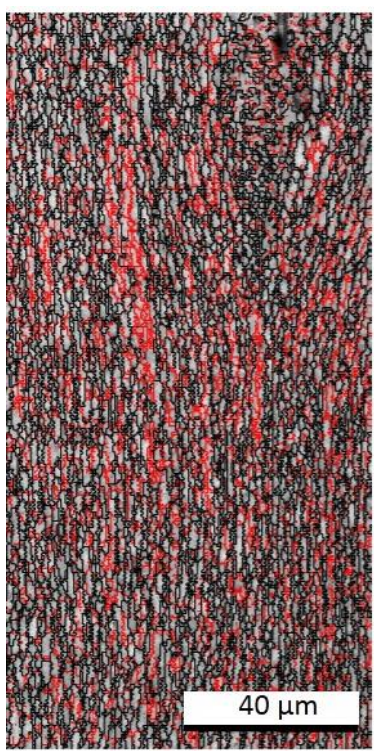



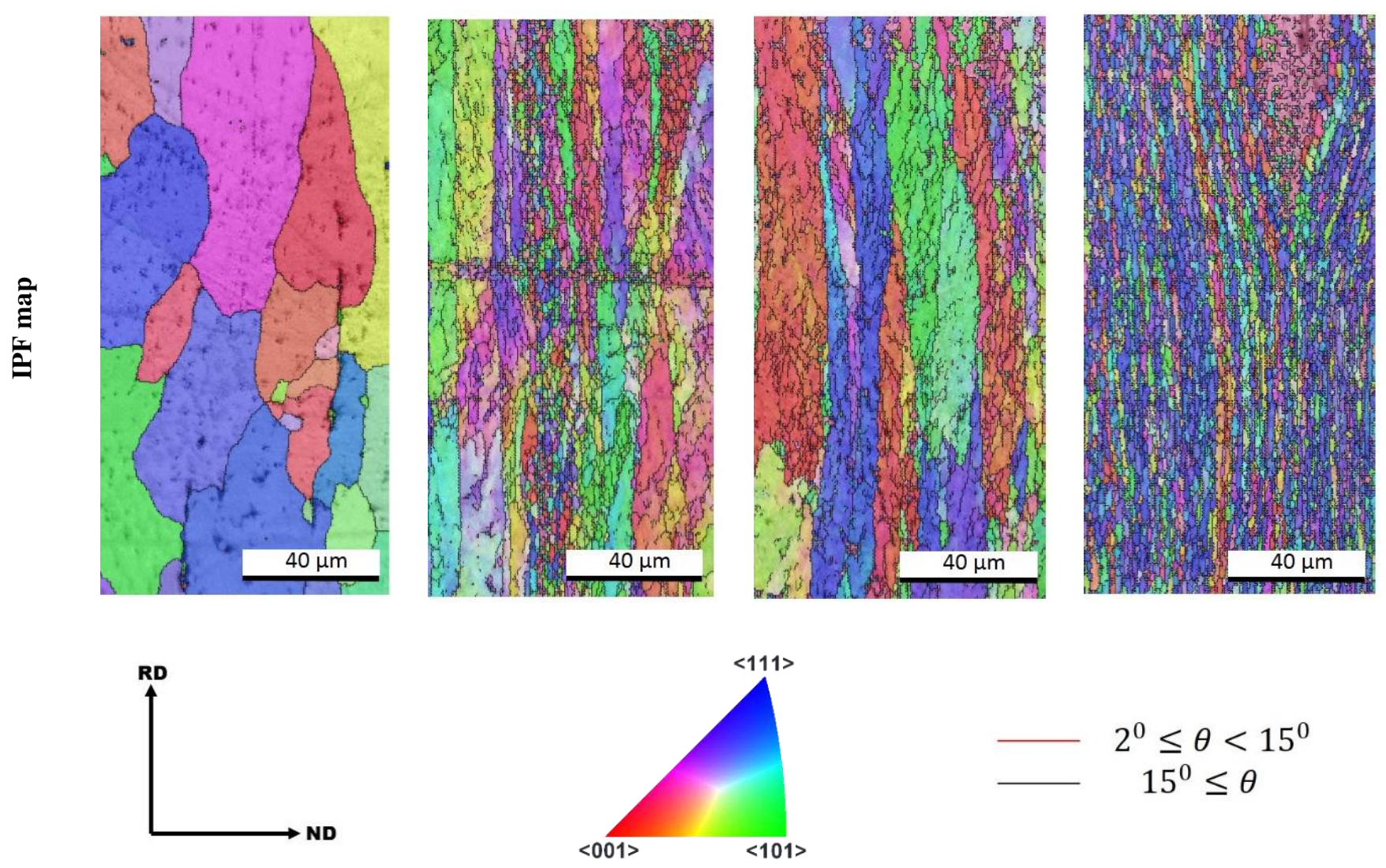

Fig. 4. Boundary misorientation map (GB) and RD inverse pole figure maps (IPF map) of WARB-ed sheets after different cycles.

Fig. 5 shows the high angle grain boundary fraction $\left(f_{\mathrm{HAGBS}}\right)$ as well as the mean misorientation angle $\left(\theta_{\mathrm{m}}\right)$ of each specimen. The low $f_{\mathrm{HAGB}}$ and $\theta_{\mathrm{m}}$ values of $40 \%$ and $8.41^{\circ}$ which were obtained after one cycle of ARB were increased to $56 \%$ and $16.42^{\circ}$, respectively, after five cycles. It can be concluded from these results that the subgrain misorientations were elevated, resulting in a balance in the distribution of the low angle and high angle boundaries. Both high angle boundary fraction and mean misorientation angle were increased by increasing the strain in the ARB procedure. 
The EBSD analysis indicated the replacement of LAGBs by HAGBs and the development of the $f_{\text {HAGBs }}$ when ARB cycles increased from one to five. According to the conventional dislocation theory, a number of dislocations are created during the first phase of deformation resulting in an intra-granular structure with thick wall cells and low angle misorientations. The cell walls' thickness is decreased by increasing the strain. Grain boundaries are formed from these walls, in turn, resulted in the creation of ultrafine grain arrays having imbalanced HAGBs [30].
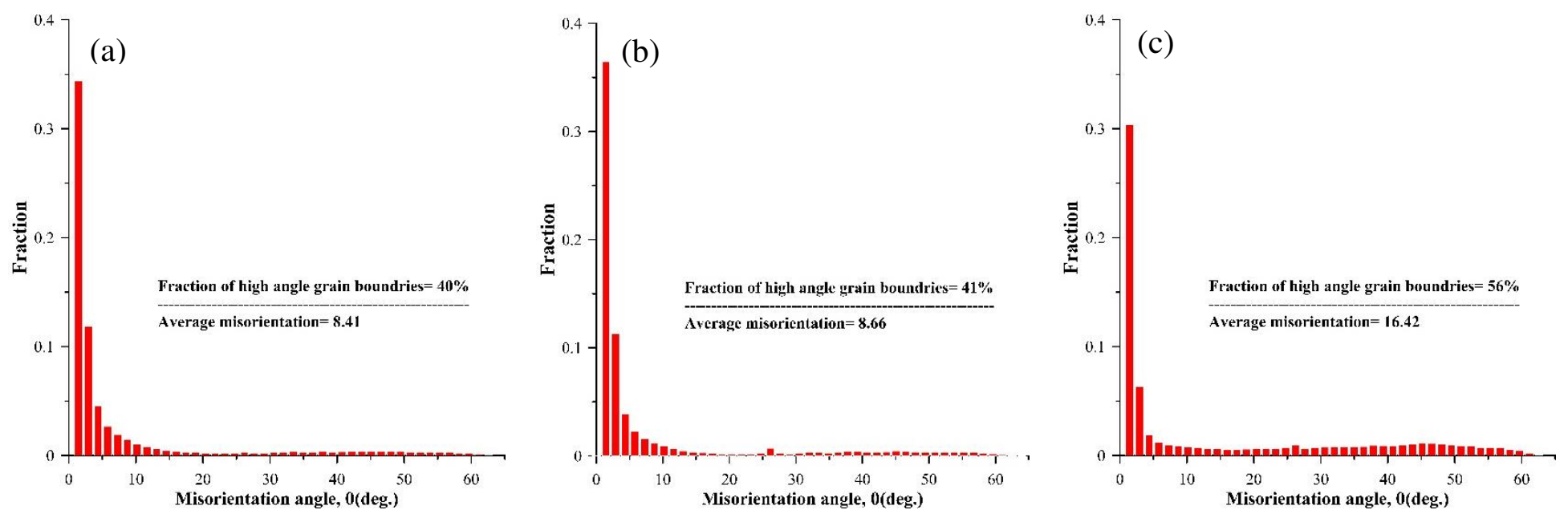

Fig. 5. Histogram of misorientation angle distribution of WARB-processed AA1050 at (a) 1, (b) 3 and (c) 5 cycles.

The AFM was utilized for evaluating the variation of surface roughness of the specimens during the ARB process. Fig. 6 represents the AFM images of the specimens after 1, 3 and 5 cycles of the ARB process. The comparison of average surface roughness $\left(R_{a}\right)$ for the studied specimens is provided in Fig. 7. As depicted in Fig. 7, increasing the number of cycles resulted in the reduction of average surface roughness. The surface roughness $\left(R_{a}\right)$ reached approximately 172 $\mathrm{nm}$ after 5 cycles, which was equal to $49 \%$ reduction compared to the 1 cycle of the ARB process. 
Previous surface roughness measurements on rolled aluminum sheets after the first cycle proving that the roughness of the strip nearly conforms to the roll surface. Afterwards, surface roughness decreases in subsequent cycles [31]. Accordingly, with increasing the number of cycles, the effectiveness of the roller on the plate surface decreases gradually. Therefore, increasing the cycles number of ARB process tend to directly decrease the average surface roughness of the sheets.
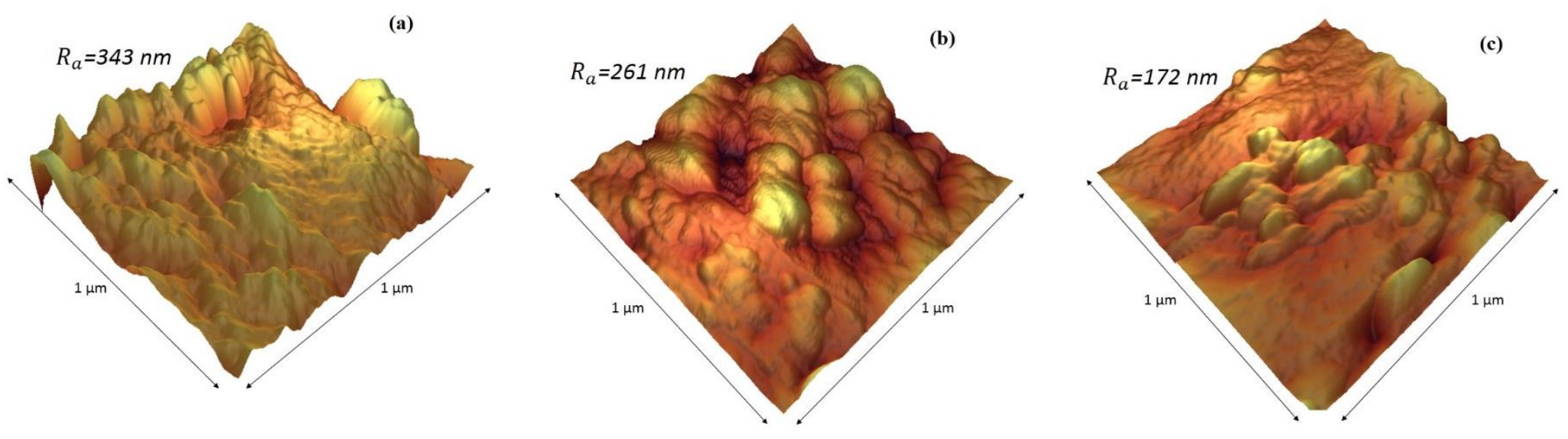

Fig. 6. AFM images of the (a) $\mathrm{C} 0$, (b) $\mathrm{C} 3$ and (c) $\mathrm{C} 5$ specimens. 


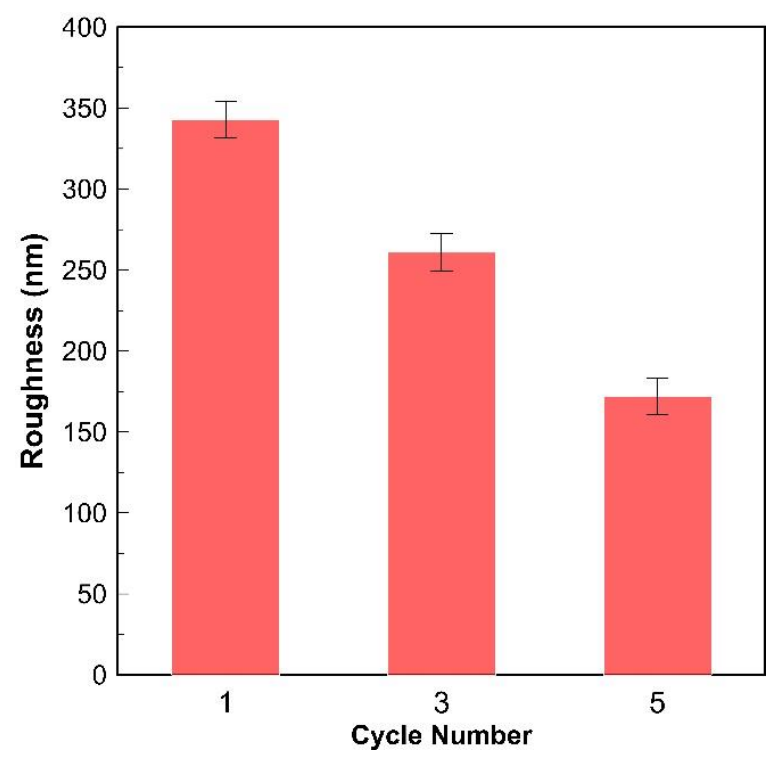

Fig. 7. The variation of average surface roughness (Ra) vs. WARB cycle.

\subsection{Mechanical properties}

Fig. 8 shows the evolution of mechanical properties of AA1050 specimens with the increase of the WARB process cycle numbers. Up to 5 cycles, there is an increasing trend for strength. Greater strength, and less elongation of these specimens after the ARB process are regarded as the natural behavior of the metals [32,20]. Also, up to five cycles, yield (YS) and ultimate tensile strengths (UTS) are enhanced as the cycle's number increases.

The first cycle has an important effect on the mechanical characteristics of the specimen. After one cycle of ARB process over the annealed specimen, the YS and UTS have been enhanced from $36 \mathrm{MPa}$ and $83 \mathrm{MPa}$ to $127 \mathrm{MPa}$ and $142 \mathrm{MPa}$, representing the enhancement by $252 \%$ for YS and $71 \%$ for UTS, respectively. Besides, the values of $146 \mathrm{MPa}$ and 161.5 MPa are obtained for these parameters through five cycles of $\mathrm{ARB}$, indicating the increases by $305 \%$ and $95 \%$, respectively, compared to the annealed specimen. These trends prove that the material strength is 
remarkably augmented through the ARB process. An important factor utilized to specify the specimen strength is the interlayer bond strength. In the primitive process cycles, there is not a sufficient bonding strength between the Al layers, and lots of porosities and discontinuities exist in the interfaces. These defects magnify the tri-axial stresses as well as stress concentrations in the strip resulting in a declined yield stress. As the number of process cycles increases, the bonding quality between the layers is promoted, leading to greater strength in the specimen $[33,34]$. It can be concluded from Fig. 8 that strain hardening or dislocation strengthening plays a significant role in the strength augmentation in the primary cycles of ARB. Also, the formation of submicron subgrains or dislocation cells can influence this strength enhancement.

Fig. 8 indicates a substantial reduction of elongation value from $46 \%$ to $17 \%$ (63\% reduction) that is realized in one cycle of ARB. A significant decline in failure strain at the first cycle is due to material strain history and fewer changes in the subsequent cycles are due to concurrently effect work hardening and mechanical recovery [35]. A declining trend in the elongation can be seen for the further cycles of the ARB process, reaching $12 \%$ after five cycles of the ARB process. The decreased ductility can be mainly ascribed by the strain hardening, in turn resulting in a declined mobility of dislocations, and therefore, the consequently reduced ductility [36,32]. Additionally, interface debonding play a significant role in this reduction. The significant growth in the number of interlayer bonds adversely affects the sheet elongation (debonding). During the tensile test, these weak interfaces cause cracks to be nucleated and propagated. 


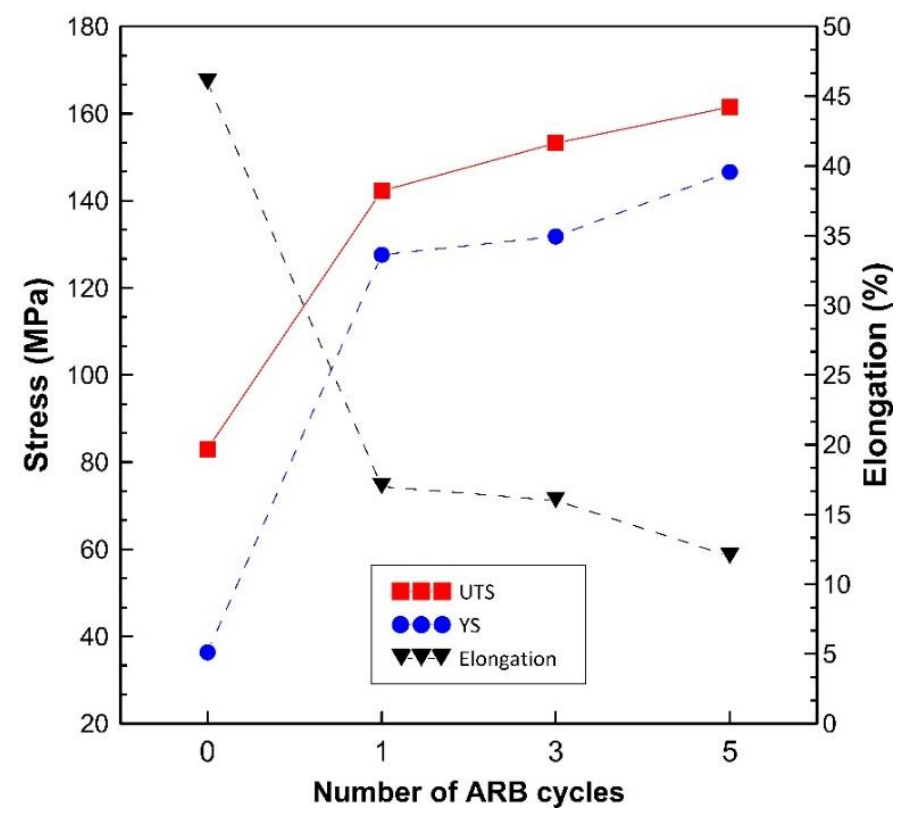

Fig. 8. Changes in the mechanical characteristics with the number of WARB cycles $(0$ cycle represent asannealed state).

\subsection{Fracture toughness}

Regarding the thin thickness of the ARB-processed samples, the plane stress fracture toughness $\left(\mathrm{K}_{\mathrm{C}}\right)$ was determined by the R-curve method. Consistent with the ASTM-E561 standard, the Rcurve can be utilized in situations where a material displays slow, and stable crack propagation under growing crack driving force, which can be seen in relatively tough materials under plane stress crack tip circumstances.

Based on the ASTM-E561 standard, prior to the test, a fatigue pre-crack should be created in the CT samples to make sure of the sharpness of the progressive crack tip. For this purpose, Zwick/Roell device was employed to create a fatigue load with a stress ratio of 0.1 and a frequency of $20 \mathrm{~Hz}$. To obtain a proper pre-crack, the loading should be continued for at least 5000 cycles or more. The mean fatigue force $\left(P_{\mathrm{m}}\right)$ of the specimens can be calculated by Eq. (2) based on the ASTM E1820 standard [28]: 
$P_{\mathrm{m}}=\frac{0.4 B b_{0}{ }^{2} \sigma_{\mathrm{y}}}{2 W+a_{0}}$

In which, $B$ and $W$ show the sample thickness and width, respectively. $b_{0}$ is the width of the notch-free zone, $\sigma_{\mathrm{y}}$ denotes the yield stress, and $a_{0}$ represents the distance between the center of pins and the end of the notch.

In this method, after the test, the variations in the crack length should be continuously calculated relative to the force variations. The changes in the length of the crack were visually measured using a high-resolution camera (48 Megapixel). For better detection and visualization of the fatigue crack, graphite coating was used due to its high light absorption and minimum reflection. In the R-curve method, the fracture toughness can be obtained at the point where R-curve and applied-curve are tangential. Based on the ASTM E561 standard, these values can be determined for CT samples using the following equations [24,25]:

$K_{r i}=\frac{P_{i}}{b \sqrt{w}} \times f_{i}\left(\frac{a}{w}\right)$

$f_{i}\left(\frac{a}{w}\right)=\left[\frac{2+(a / w)}{(1-(a / w))^{3 / 2}}\right] \times\left[0.886+4.64\left(\frac{a}{w}\right)-13.32\left(\frac{a}{w}\right)^{2}+14.72\left(\frac{a}{w}\right)^{3}-5.6\left(\frac{a}{w}\right)^{4}\right]$

In the above equations, $a$ shows the crack length relative to the applied force $\left(P_{\mathrm{i}}\right)$, and $b$ and $w$ are the thickness and width of the CT sample, respectively.

Fig. 9 demonstrates examples of the fractured samples. Plane stress fracture toughness was determined based on Eq. 3 for each cycle of ARB. Fig. 10 shows the R-curve for the first, third, 
and fifth cycles of WARB as well as the initial sample before the processing. Additionally, $K_{\mathrm{r}}$ is plotted for three fixed forces as a function of the crack length (dashed line). The intersection of the R-curve with the constant lines indicates the value of $K_{\mathrm{c}}$. This means that when the stress intensity factor is equal to the fracture resistance, the crack will unsteadily start to grow. In Figs. 10(a-d), one step increment after the intersection of the two curves leads to a situation in which the stress intensity factor supersedes the resistance of the substance indicating the unsteady growth of the crack.

To assess the reproducibility of the results and their validation, each state was tested three times. Fig. 11 depicts $K_{\mathrm{c}}$ values of each cycle for three replicates as well as their mean values. As seen, the results of all three cycles were close to each other, showing a relative consistency.

After the first WARB cycle, fracture toughness increased from 12.85 to $18.11 \mathrm{MPa} \cdot \mathrm{m}^{1 / 2}$, showing a $41 \%$ increment, which can be assigned to the increase of the strength after the first cycle as compared to the base state $(\mathrm{C} 0)$. The increasing trend of the fracture toughness continued with the progress of $\mathrm{ARB}$ cycles, and at the fifth cycle, the fracture toughness showed a $78 \%$ increment compared to the annealed sample. In metallic materials, strength and ductility can remarkably affect the fracture toughness variations. ARB process often involves an increase in the strength while ductility experiences a decline. Studies have shown that the effect of strength increase is more dominant compared to the declining trend of ductility $[24,26]$. In the present work, during the first to fifth cycles, fracture toughness increased with raising the strength. Such a trend was previously observed in the case of copper samples under the CGP process [37]. This trend was, however, different in the case of the ECAP process in a way that the fracture toughness of aluminum and nickel samples declined after the first pass of the ECAP process, which turned into an ascending trend from the second pass $[38,23]$. 
On the other hand, the grain size decreased by increasing the number of WARB cycles (Fig. 4), and the grain size reached $1.8 \mu \mathrm{m}$ after the fifth cycle. Therefore, it can be said that from the third cycle onwards, the effect of cold work decreases and grain refinement increases the fracture toughness in the last cycles.

As the UFG materials are associated with higher grain boundaries, volume fraction, crack tip blunting, and crack arrest have much more main contributions in fracture resistance, which in turn result in the augmentation of fracture toughness [23]. Based on the claims and according to Figs. 4 and 5, a severe increase in the $f_{\text {HAGBs }}$ and the raise in the $\theta_{\mathrm{m}}$ were the main reasons for fracture toughness increase in the C5 specimens.

Moreover, the decrease in the grain sizes intensifies some mechanisms like grain boundary accommodation, grain boundary triple junction activity, grain nucleation, as well as grain rotation [24]. An increase in the fracture toughness is anticipated to occur after grain refinement, as the rate of the nano-scale plastic energy release is controlled by these mechanisms [39,23]. Some experimental studies on metals proved that after grain refinement, the hardening region such as the plastic zone is enlarged [40,41]. This can be considered as a reason for fracture resistance improvement detected in the UFG materials, among others.

To the best knowledge of authors, Rahmatabadi et al. [24] were the only group who calculated the fracture toughness of ARB-processed AA1050 sheets. After five ARB cycles at room temperature, they reported that the plane stress fracture toughness $\left(K_{\mathrm{c}}\right)$ reached $24 \mathrm{MPa} \cdot \mathrm{m}^{1 / 2}$, exhibiting a $142 \%$ increase compared to the initial sample (before ARB). This increase was, however, different in this study as a $78 \%$ rise was observed in $K_{\mathrm{c}}$ in the fifth cycle, which is remarkably lower than the $142 \%$ increase in [24]. For explaining this difference, three points should be mentioned: 
i. As mentioned before, during the ARB process, the increasing trend of strength is closely related to the rise in fracture toughness. In the current study, as ARB was carried out at elevated temperatures, although rolling caused grain refinement and severely decreased the grain size, some grain growth occurred due to the high temperature. Thus the grain size is expected to be larger than the case of room temperature rolling. This caused an increase in the strength of the samples in the work of Rahmatabadi et al.[24] up to 200 $\mathrm{MPa}$, while this value was $161.5 \mathrm{MPa}$ in the present research.

ii. Rahmatabadi et al. [24] reported the $K_{\mathrm{c}}$ value of the initial sample as $9.9 \mathrm{MPa} \cdot \mathrm{m}^{1 / 2}$, which is 12.85 in the current study. The lower value of $K_{\mathrm{c}}$ of the annealed sample (which is the base of the comparison) resulted in the relative difference of toughness of $142 \%$ in their work. The important point is that $K_{\mathrm{c}}=9.9 \mathrm{MPa} \cdot \mathrm{m}^{1 / 2}$ for the annealed sample is directly related to the grain size of the initial samples. Their report contained no information about the grain size investigations. Probably, the precursors' preparation method and then annealing condition resulted in the drastic growth of grain size, giving rise to a coarser structure compared to the $\mathrm{C} 0$ sample of the present research. According to Fig. 4, the annealed sheet of the current study had the mean grain size of $35 \mu \mathrm{m}$ and UTS of 83 $\mathrm{MPa}$, while this value was $61 \mathrm{MPa}$ in the work of Rahamtabadi et al. [24], Which justifies the above argument.

iii. Based on the ASTM E561 standard, fatigue load should be applied at the beginning of the test to create the pre-crack. The presence of this fatigue pre-crack results in uniform and proper rupture of the CT sample during the tensile test due to the sharp tip of the crack. The fatigue pre-crack was not created in the work of Rahamtbadi et al. [24], and only simple stretching was applied. This could be another reason for the deviation of the 
results, as in the absence of sharp-tip pre-crack, more tensile force will be used for the opening of the notch. According to Eq. (3), the increase in the initial force can enhance the value of $K_{\mathrm{c}}$, which seems to occur in their work.

According to the mentioned reasons, it can be claimed that the $78 \%$ increase in $K_{\mathrm{c}}$ (compared to that of the $\mathrm{C} 0$ ) is close to reality and can be documented.

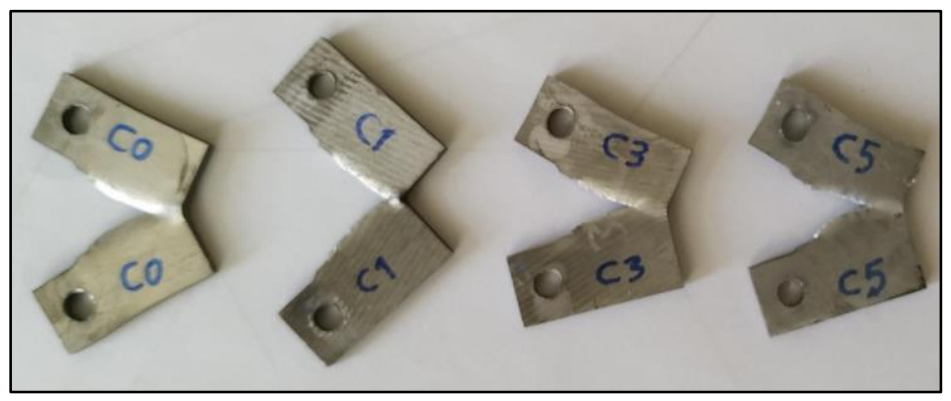

Fig. 9. Some of the fractured CT specimens (C0, C1, C3 and C5 corresponds to annealed and WARB-ed samples at 1, 3 and 5 cycles, respectively).

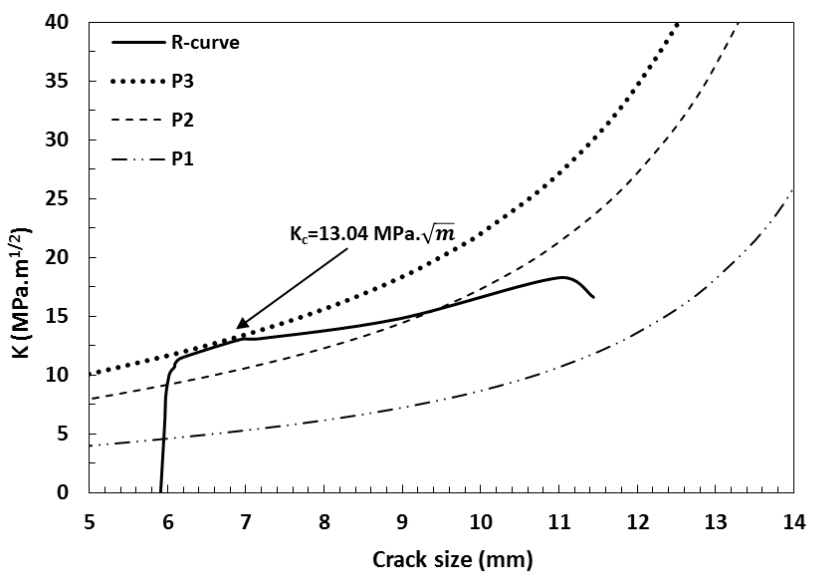

(a)

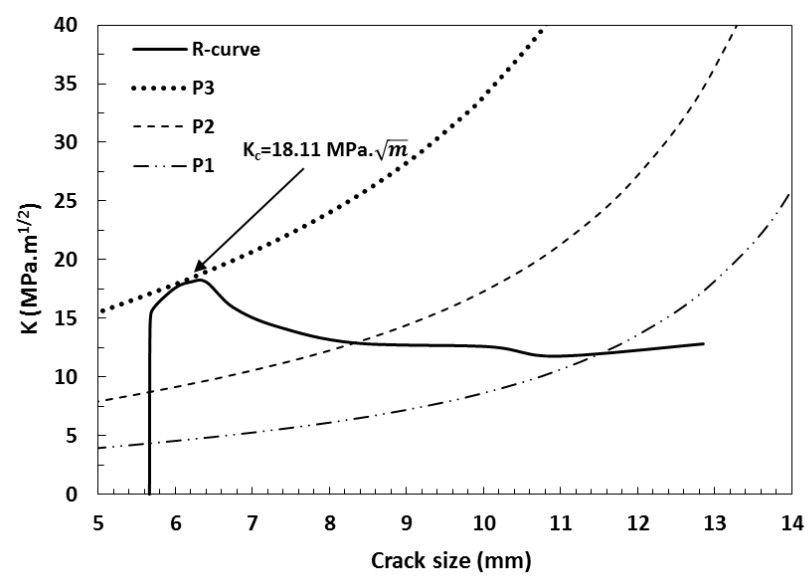

(b) 


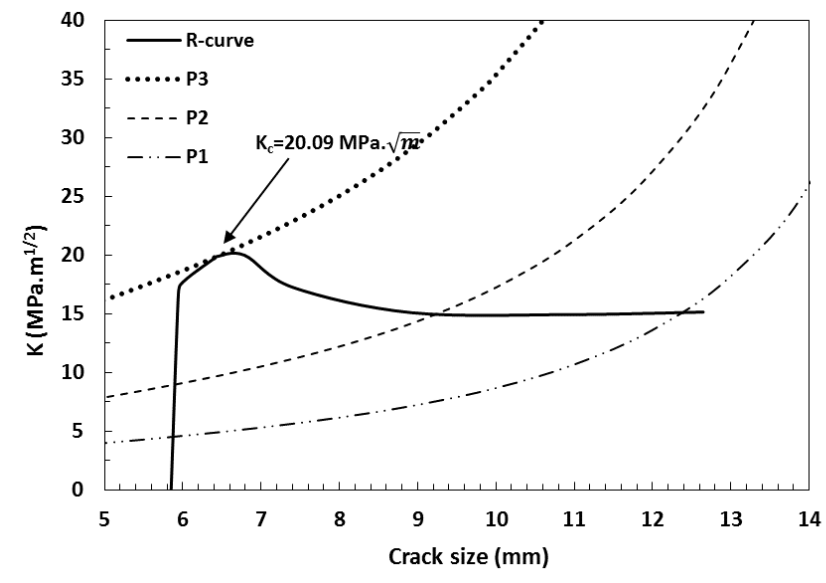

(c)

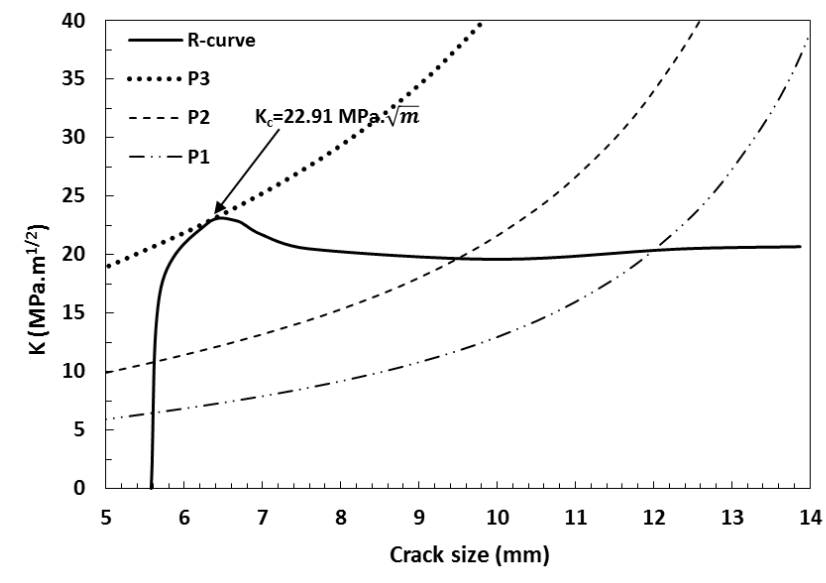

(d)

Fig. 10. R-curves for AA1050 processed by WARB at (a) 0, (b) 1, (c) 3 and (d) 5 cycles (0 cycle represent as-annealed state).

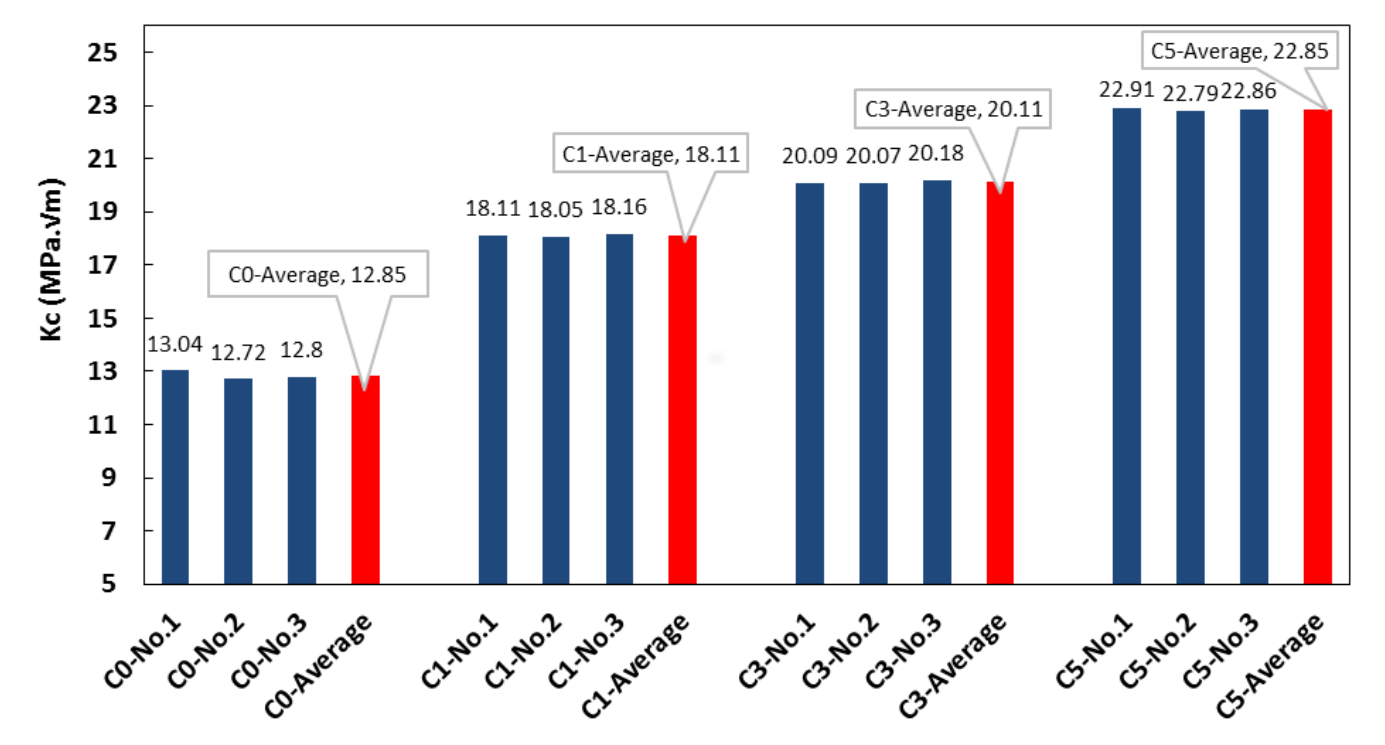

Fig. 11. Fracture toughness variations in different cycles of the WARB process $(\mathrm{C} 0, \mathrm{C} 1, \mathrm{C} 3$ and $\mathrm{C} 5$ corresponds to annealed and WARB-ed samples at 1, 3 and 5 cycles, respectively). 


\subsection{Fractography}

SEM imaging of the CT samples after the loading can remarkably help to understand the failure mechanisms of these samples. Therefore, the cross-section of the samples was investigated after the fracture. Fig. 12 shows the fracture surface of the sample after one ARB cycle. Based on the ASTM E561 standard, two types of loading were applied to the CT samples to determine the fracture toughness. First, an oscillating loading was applied to create fatigue pre-crack until the crack tip is sharpened and then a constant tensile loading in a quasi-static manner. In Fig. 12(a), zone 1 and zone 2 show the oscillating and constant loading regions, respectively. As seen, the fatigue cracks fully encompassed the thickness of zone 1 and were uniformly distributed. In Zone 2, however, a ductile rupture can be seen, which resulted in the substance flow from the sides to the center (necking) and hence the ultimate failure of the sample along a relatively

narrow line. It is expected that this relatively narrow failure line in the center of the zone 2 broadens by increasing the number of ARB cycles and hence the rise in the strength and stiffness of the samples giving rise to milder ductile rupture.

Fig. 12(b) shows more details of the fatigue crack propagation area at higher resolution; numerous fine ripple veins can be seen in this region, indicating the mild crack propagation. Moreover, tiny cliffs can be observed parallel to the crack propagation with regular arrangement relative to a specific orientation. The distance between these tiny cliffs or saw-teeth is a function of oscillating loading frequency as their distance declined by increasing the frequency and vice versa [42]. The oscillating load frequency was $20 \mathrm{~Hz}$ in this study. This phenomenon could also be assigned to the lateral sliding of the crack tip during the growth of the fatigue cracks. During this path, the resistance against crack growth increased and led to expandable difficulties. Moreover, some deformations may occur in grain boundary junction, which is a part of grain 
layer fracture [43]. Fig. 12(c) depicts zone 1 at lower magnification in which furrow and hollow can be observed. This phenomenon can be due to the adjacent crack grow up, giving rise to tearing and then resulting in a furrow and hollow in the fractured surface because of the continuous movement of crack during its closing and opening.

Fig. 12(d) illustrates the central part of zone 2. Here, a layered bond can be observed after the failure. As the sample experiences one ARB cycle, only one inter-layer line can be seen, indicating the delamination in the bond interfaces. Fig. 12(e) shows some of the dimples in zone 2 at high magnification in the fractured surface created by the tensile load. These dimples should be investigated in terms of shape, elongation, size, and depth to determine the ductile rupture properties.

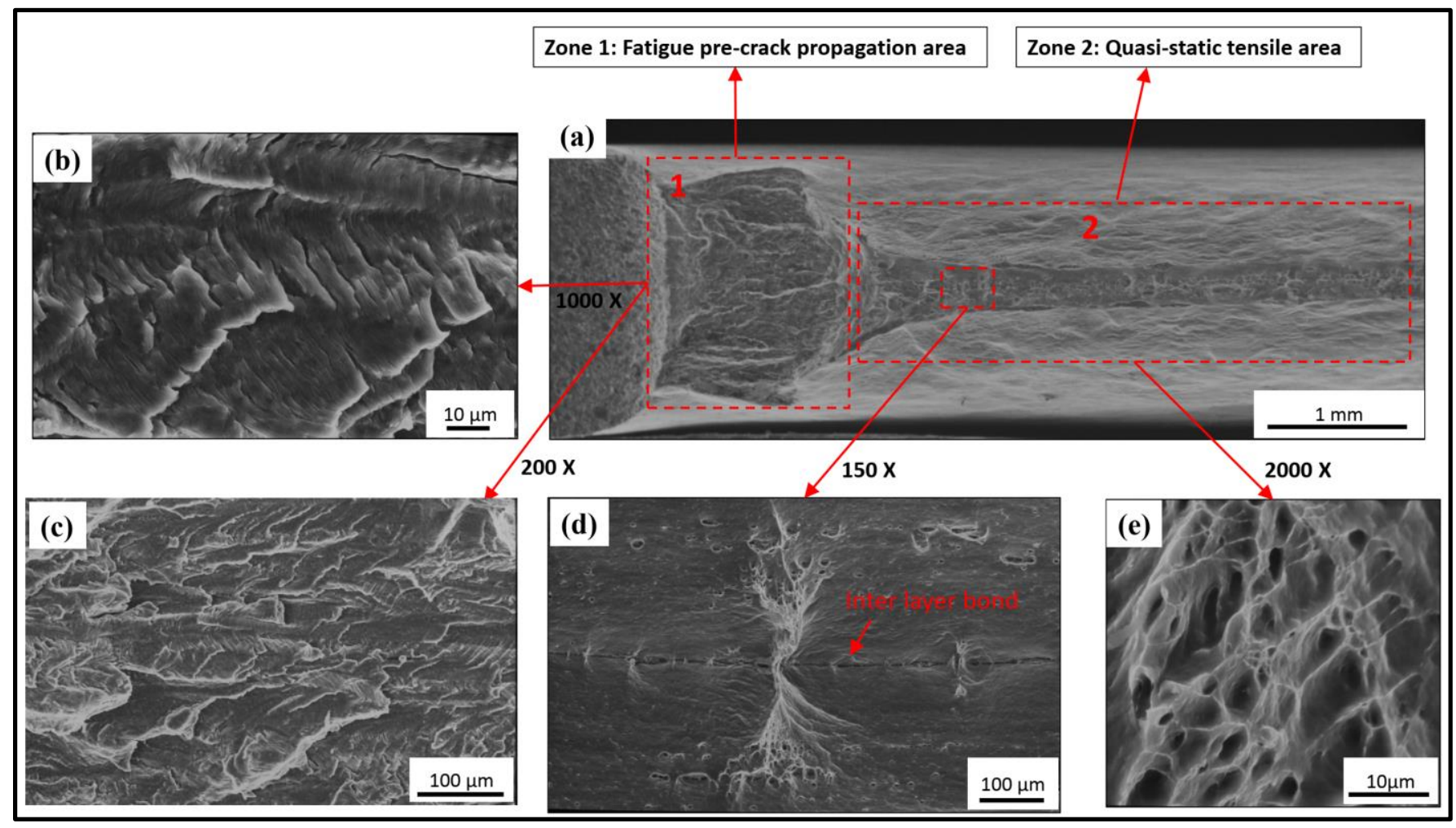

Fig. 12. A comprehensive view of the CT specimen fracture surface after 1 cycle WARB. 
Fig. 13 depicts the shear zones and dimples, which are the major characteristics of a ductile fracture after compact tension test. Ductile fracture often occurs in several stages, including the initial nucleation from microvoids, their growth, and finally their combination along a central line $[44,45]$. Ductile fracture generally occurs in metals with high toughness and proper flexibility, including AA1050 alloy. Hemispherical and equiaxed dimples and gray fibrous are among the characteristic features of this failure. The dimples can be discussed in terms of elongation, size, and depth. This trend is often observed in FCC crystals [46,47].

Fig. 13(a) shows the initial sample before the WARB process indicating larger, deep, equiaxed, non-elongated, and semi-spherical dimples. A closer look in Fig. 13 shows that as WARB process cycles went on, the dimples got smaller, more elongated, and shallower, indicating shear ductile rupture (Fig. 13(b-d)). The appearance and orientation of the dimples determine the tensile loading and the growth direction on the fractured surface. More elongated, shallower, and smaller dimples can be attributed to non-uniform plastic strain on the fractured surface due to the shear stresses $[45,48]$. In fact, elongated voids and their parabolic dimples all suggest shear stress-induced failure whose maximal condition can be observed after five cycles in Fig. 13(d) which enhanced the tensile strength while decreasing the elongation.
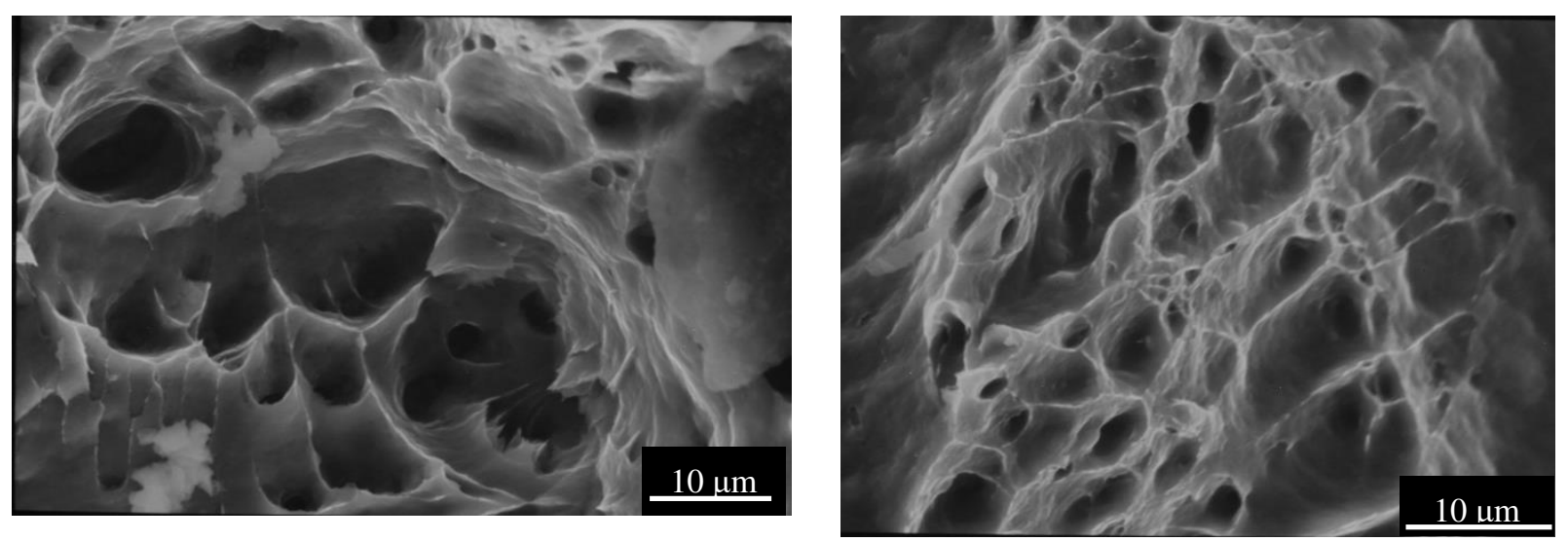
(a)

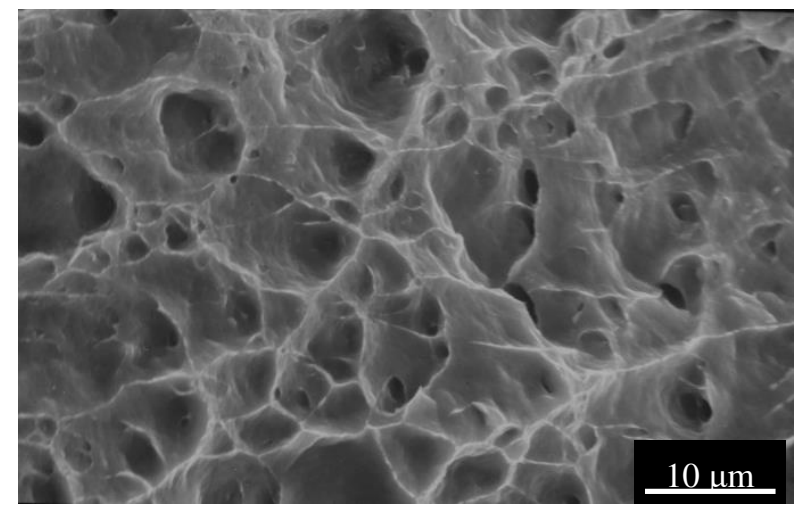

(c) (b)

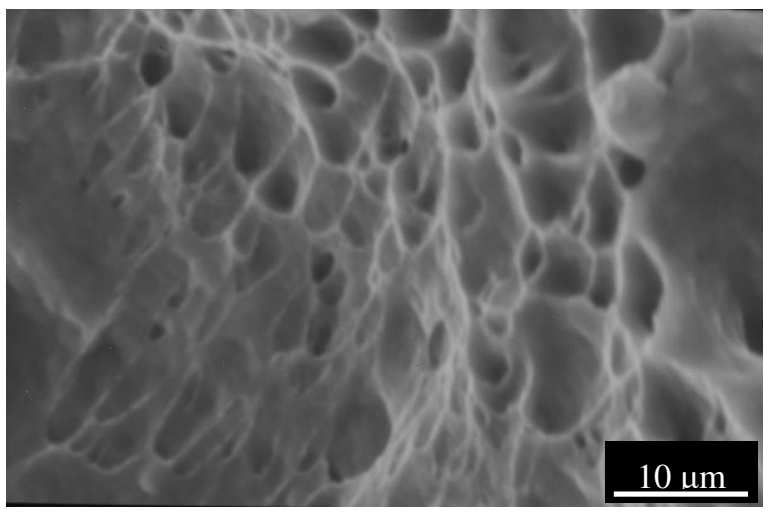

(d)

Fig. 13. High magnification of CT specimen fractured surface after (a) annealing, (b) 1, (c) 3 and (d) 5 cycles WARB process.

\section{Conclusions}

In the present research, for the first time the influence of warm accumulative roll bonding on the plane stress fracture toughness of AA1050 sheets was investigated in various cycles. For a better understanding of the variations of fracture toughness, mechanical behavior, microstructural evolution, and CT specimen fracture surface were examined. The results can be summarized as:

1. The results indicated that an increase in the number of cycles enhanced the fracture toughness in such a way that the $K_{\mathrm{c}}$ of the final cycles $\left(22.85 \mathrm{MPa} \cdot \mathrm{m}^{1 / 2}\right)$ showed a $78 \%$ increase compared to the initial sample $\left(12.85 \mathrm{MPa} \cdot \mathrm{m}^{1 / 2}\right.$ before the processing. The first cycle caused a severe increase in $K_{\mathrm{c}}(41 \%)$.

2. Fracture toughness changes and UTS, and $f_{\text {HAGBs }}$ are closely correlated. WARB enhanced the UTS by $95 \%$, and $f_{\mathrm{HAGBs}}$ experienced an ascending trend and reached $56 \%$ in the fifth cycle. On the contrary, WARB decreased the grain size from 35 to $1.8 \mu \mathrm{m}$. 
3. A comparison between the present work and previous studies showed a proper consistency between the variation trend of fracture toughness during warm and cold ARB as both of these processes enhanced the fracture toughness. Despite their consistency, the differences in the results can be assigned to the temperature of the process, grain size, and the strength of the raw materials, as well as the fatigue pre-crack creation in the CT specimens before the test.

4. SEM images were taken for the first time from the fracture surface of WARB-process CT samples (aluminum). Two separate zones can be observed on the fracture surface: fatigue pre-crack propagation area, which was related to the oscillating loading (Zone 1), and quasi-static tensile area (Zone 2). Tiny cliffs and furrow and hollows were the dominant phenomena in zone 1, while zone 2 exhibited strong signs of shear ductile rupture. After several cycles, elongated, shallow, and parabolic dimples emerged in this zone.

5. The repeating of the ARB process was found to significantly contribute to a decreased surface roughness of the samples, and the AFM images showed that the average roughness at the fifth cycle was $49 \%$ lower than that of the first cycle.

The authors believe that this research can be further developed in the future. The next step could be developing the method for other aluminum alloys or even other metals. Also, in the continuation of the present study, it is interesting to investigate the effect of different temperatures in the WARB process on the final fracture toughness.

\section{Funding}

The authors did not receive support from any organization for the submitted work.

\section{Conflict of interests}

The authors declare that they have no conflict of interest. 


\section{Availability of data and material}

The raw/processed data required to reproduce these findings cannot be shared at this time due to legal or ethical reasons.

\section{Code availability}

Not applicable.

\section{Ethics approval}

The work described above has not been published previously. Moreover, the present manuscript is not under consideration for publication elsewhere and which is approved by all authors.

\section{References}

1. Hongyu W, Jie W, Fei T, Ting L, Juncai S, Xiangwei K, Dianhua Z, Wen P, Shunhu Z (2020) Analysis and simulation for shape control effects of square aluminum tube during ECAP. The International Journal of Advanced Manufacturing Technology 108 (11):3859-3870. doi:10.1007/s00170-020-05489-2

2. Wroński M, Wierzbanowski K, Malik R, Wroński S, Wojtas D, Baczmański A, Tarasiuk J (2020) Microstructure Characteristics of ECAP Processed 1050 Aluminum After Deformation and 5 Years Later. Metals and Materials International. doi:10.1007/s12540-020-00817-3

3. Yusuf SM, Hoegden M, Gao N (2020) Effect of sample orientation on the microstructure and microhardness of additively manufactured AlSi10Mg processed by high-pressure torsion. The International Journal of Advanced Manufacturing Technology 106 (9):4321-4337. doi:10.1007/s00170019-04817-5

4. Ghorbanhosseini S, Fereshteh-Saniee F, Sonboli A (2020) An experimental investigation on the influence of elevated-temperature constrained groove pressing on the microstructure, mechanical properties, anisotropy and texture of $2024 \mathrm{Al}$ sheets. Journal of Alloys and Compounds 817:152763. doi:https://doi.org/10.1016/j.jallcom.2019.152763

5. Zabihi M, Emadoddin E, Qods F (2020) Processing of Al/Al 2 O 3 Composite Using Simple Shear Extrusion (SSE) Manufactured by Powder Metallurgy (PM). Metals and Materials International 26 (1):113

6. Khatami R, Fattah-alhosseini A, Mazaheri Y, Keshavarz MK, Haghshenas M (2017) Microstructural evolution and mechanical properties of ultrafine grained AA2024 processed by accumulative roll bonding. The International Journal of Advanced Manufacturing Technology 93 (1):681-689. doi:10.1007/s00170-017-0547-z

7. Chekhonin P, Zöllner D, Zimmer E, Scharnweber J, Romberg J, Skrotzki W (2019) Microstructure of accumulative roll bonded high purity aluminium laminates. Materialia 5:100236

8. Wang Y, Zhong F, Wu R, Wu H, Turakhodjaev N, Kudratkhon B, Sun J, Hou L, Zhang J, Li X, Zhang M (2020) High-strength, ductility and modulus Al-Li/B4C composite with near nanostructure produced by accumulative roll bonding. Journal of Alloys and Compounds 834:155105. doi:https://doi.org/10.1016/j.jallcom.2020.155105

9. Morovvati MR, Mollaei-Dariani B (2018) The formability investigation of CNT-reinforced aluminum nano-composite sheets manufactured by accumulative roll bonding. The International Journal of Advanced Manufacturing Technology 95 (9):3523-3533. doi:10.1007/s00170-017-1205-1

10. Saito Y, Utsunomiya H, Tsuji N, Sakai T (1999) Novel ultra-high straining process for bulk materials - development of the accumulative roll-bonding (ARB) process. Acta materialia 47 (2):579-583 
11. Mokhles M, Hosseini M, Danesh-Manesh H, Zebarjad SM (2020) Structure and mechanical properties of $\mathrm{Ni} / \mathrm{Ti}$ multilayered composites produced by accumulative roll-bonding process. Journal of Composite Materials 54 (8):1119-1126

12. Mansouri H, Eghbali B, Afrand M (2019) Producing multi-layer composite of stainless steel/aluminum/copper by accumulative roll bonding (ARB) process. Journal of Manufacturing Processes 46:298-303

13. Azimi M, Toroghinejad MR, Shamanian M, Kestens LAI (2018) Grain and texture evolution in nano/ultrafine-grained bimetallic $\mathrm{Al} / \mathrm{Ni}$ composite during accumulative roll bonding. Journal of Materials Science 53 (17):12553-12569. doi:10.1007/s10853-018-2510-2

14. Rahmatabadi D, Mohammadi B, Hashemi R, Shojaee T (2018) An experimental study of fracture toughness for nano/ultrafine grained $\mathrm{Al} 5052 / \mathrm{Cu}$ multilayered composite processed by accumulative roll bonding. Journal of Manufacturing Science and Engineering 140 (10)

15. Mishin OV, Zhang YB, Godfrey A (2017) The influence of multiscale heterogeneity on recrystallization in nickel processed by accumulative roll bonding. Journal of Materials Science 52 (5):2730-2745. doi:10.1007/s10853-016-0566-4

16. Ye N, Ren X, Liang J (2020) Microstructure and mechanical properties of Ni/Ti/Al/Cu composite produced by accumulative roll bonding (ARB) at room temperature. Journal of Materials Research and Technology 9 (3):5524-5532. doi:https://doi.org/10.1016/j.jmrt.2020.03.077

17. Arigela VG, Palukuri NR, Singh D, Kolli SK, Jayaganthan R, Chekhonin P, Scharnweber J, Skrotzki W (2019) Evolution of microstructure and mechanical properties in 2014 and 6063 similar and dissimilar aluminium alloy laminates produced by accumulative roll bonding. Journal of Alloys and Compounds 790:917-927. doi:https://doi.org/10.1016/j.jallcom.2019.03.231

18. Sun Y, Chen Y, Tsuji N, Guan S (2020) Microstructural evolution and mechanical properties of nanostructured $\mathrm{Cu} / \mathrm{Ni}$ multilayer fabricated by accumulative roll bonding. Journal of Alloys and Compounds 819:152956. doi:https://doi.org/10.1016/j.jallcom.2019.152956

19. Su L, Lu C, Li H, Deng G, Tieu K (2014) Investigation of ultrafine grained AA1050 fabricated by accumulative roll bonding. Materials Science and Engineering: A 614:148-155

20. Wang Z, Ma M, Qiu Z, Zhang J, Liu W (2018) Microstructure, texture and mechanical properties of AA 1060 aluminum alloy processed by cryogenic accumulative roll bonding. Materials Characterization 139:269-278

21. Pippan R, Hohenwarter A (2016) The importance of fracture toughness in ultrafine and nanocrystalline bulk materials. Materials Research Letters 4 (3):127-136. doi:10.1080/21663831.2016.1166403

22. Sabirov I, Valiev RZ, Semenova IP, Pippan R (2010) Effect of Equal Channel Angular Pressing on the Fracture Behavior of Commercially Pure Titanium. Metallurgical and Materials Transactions A 41 (3):727-733. doi:10.1007/s11661-009-0111-z

23. Darban H, Mohammadi B, Djavanroodi F (2016) Effect of equal channel angular pressing on fracture toughness of Al-7075. Engineering Failure Analysis 65:1-10

24. Rahmatabadi D, Hashemi R, Mohammadi B, Shojaee T (2017) Experimental evaluation of the plane stress fracture toughness for ultra-fine grained aluminum specimens prepared by accumulative roll bonding process. Materials Science and Engineering: A 708:301-310

25. Tayyebi M, Rahmatabadi D, Adhami M, Hashemi R (2019) Influence of ARB technique on the microstructural, mechanical and fracture properties of the multilayered Al1050/Al5052 composite reinforced by SiC particles. Journal of Materials Research and Technology 8 (5):4287-4301

26. Rahmatabadi D, Tayyebi M, Sheikhi A, Hashemi R (2018) Fracture toughness investigation of Al1050/Cu/MgAZ31ZB multi-layered composite produced by accumulative roll bonding process. Materials Science and Engineering: A 734:427-436

27. Testing ASf, Materials (2005) Standard Test Method for KR Curve Determination. E561. ASTM International,

28. Standard A (2001) Standard test method for measurement of fracture toughness. ASTM, E1820-01. 
29. Schwartz AJ, Kumar M, Adams BL, Field DP (2009) Electron backscatter diffraction in materials science, vol 2. Springer,

30. Valiev R, Korznikov A, Mulyukov R (1993) Structure and properties of ultrafine-grained materials produced by severe plastic deformation. Materials Science and Engineering: A 168 (2):141-148

31. Le HR, Sutcliffe MPF (2000) Analysis of surface roughness of cold-rolled aluminium foil. Wear 244 (1):71-78. doi:https://doi.org/10.1016/S0043-1648(00)00441-5

32. Alvand M, Naseri M, Borhani E, Abdollah-Pour H (2017) Nano/ultrafine grained AA2024 alloy processed by accumulative roll bonding: a study of microstructure, deformation texture and mechanical properties. Journal of Alloys and Compounds 712:517-525

33. Dehghan M, Qods F, Gerdooei M, Mohammadian-Semnani H (2020) Comparative Study of the Planar Uniformity of the Mechanical Properties of the AA1050 Strips Processed by Conventional and Cross Accumulative Roll-Bonding Techniques. JOM 72 (4):1571-1579. doi:10.1007/s11837-020-04035-5 34. Jamaati R, Toroghinejad MR (2010) Effect of friction, annealing conditions and hardness on the bond strength of Al/Al strips produced by cold roll bonding process. Materials \& Design 31 (9):4508-4513

35. Morovvati MR, Dariani BM (2017) The effect of annealing on the formability of aluminum 1200 after accumulative roll bonding. Journal of Manufacturing Processes 30:241-254. doi:https://doi.org/10.1016/j.jmapro.2017.09.013

36. Naseri M, Reihanian M, Borhani E (2016) A new strategy to simultaneous increase in the strength and ductility of AA2024 alloy via accumulative roll bonding (ARB). Materials Science and Engineering: A 656:12-20

37. Mohammadi B, Tavoli M, Djavanroodi F (2014) Effects of Constrained Groove Pressing (CGP) on the plane stress fracture toughness of pure copper. Structural Engineering and Mechanics 52 (5):957-969

38. Hohenwarter A, Pippan R (2011) Fracture toughness evaluation of ultrafine-grained nickel. Scripta Materialia 64 (10):982-985

39. Latapie A, Farkas D (2004) Molecular dynamics investigation of the fracture behavior of nanocrystalline $\alpha$-Fe. Physical Review B 69 (13):134110

40. Cherukuri B, Nedkova TS, Srinivasan R (2005) A comparison of the properties of SPD-processed AA-6061 by equal-channel angular pressing, multi-axial compressions/forgings and accumulative roll bonding. Materials Science and Engineering: A 410:394-397

41. Ekiz E, Lach T, Averback R, Mara N, Beyerlein I, Pouryazdan M, Hahn H, Bellon P (2014) Microstructural evolution of nanolayered $\mathrm{Cu}-\mathrm{Nb}$ composites subjected to high-pressure torsion. Acta materialia 72:178-191

42. Lynch S (2017) Some fractographic contributions to understanding fatigue crack growth. International Journal of Fatigue 104:12-26. doi:https://doi.org/10.1016/j.ijfatigue.2017.06.036

43. Chao X, Yang SL Analysis on fatigue crack propagation and fractography of A7075 aluminum alloy. In: Applied Mechanics and Materials, 2012. Trans Tech Publ, pp 390-394

44. Shaarbaf M, Toroghinejad MR (2008) Nano-grained copper strip produced by accumulative roll bonding process. Materials Science and Engineering: A 473 (1-2):28-33

45. Pasebani S, Toroghinejad MR (2010) Nano-grained 70/30 brass strip produced by accumulative rollbonding (ARB) process. Materials Science and Engineering: A 527 (3):491-497

46. Hertzberg RW (1997) Deformation and fracture mechanics of engineering materials, vol 19. Journal of Materials Education.

47. Barsoum I, Faleskog J (2007) Rupture mechanisms in combined tension and shear-Experiments. International Journal of Solids and Structures 44 (6):1768-1786. doi:https://doi.org/10.1016/j.ijsolstr.2006.09.031

48. Raei M, Toroghinejad MR, Jamaati R (2011) Nano/ultrafine structured AA1100 by ARB process. Materials and Manufacturing Processes 26 (11):1352-1356 
Figures
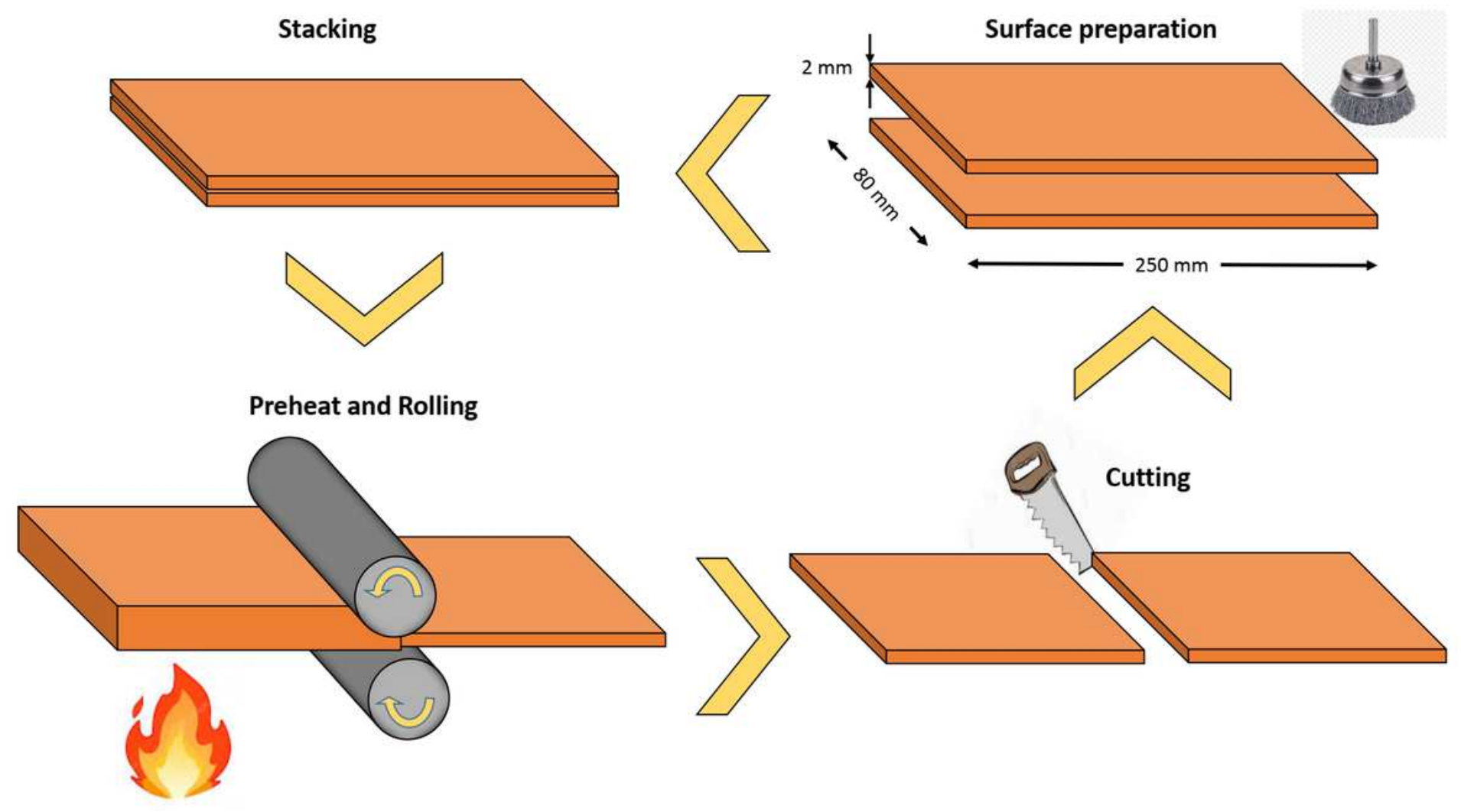

Figure 1

Schematic design of the WARB procedure. 
(a)

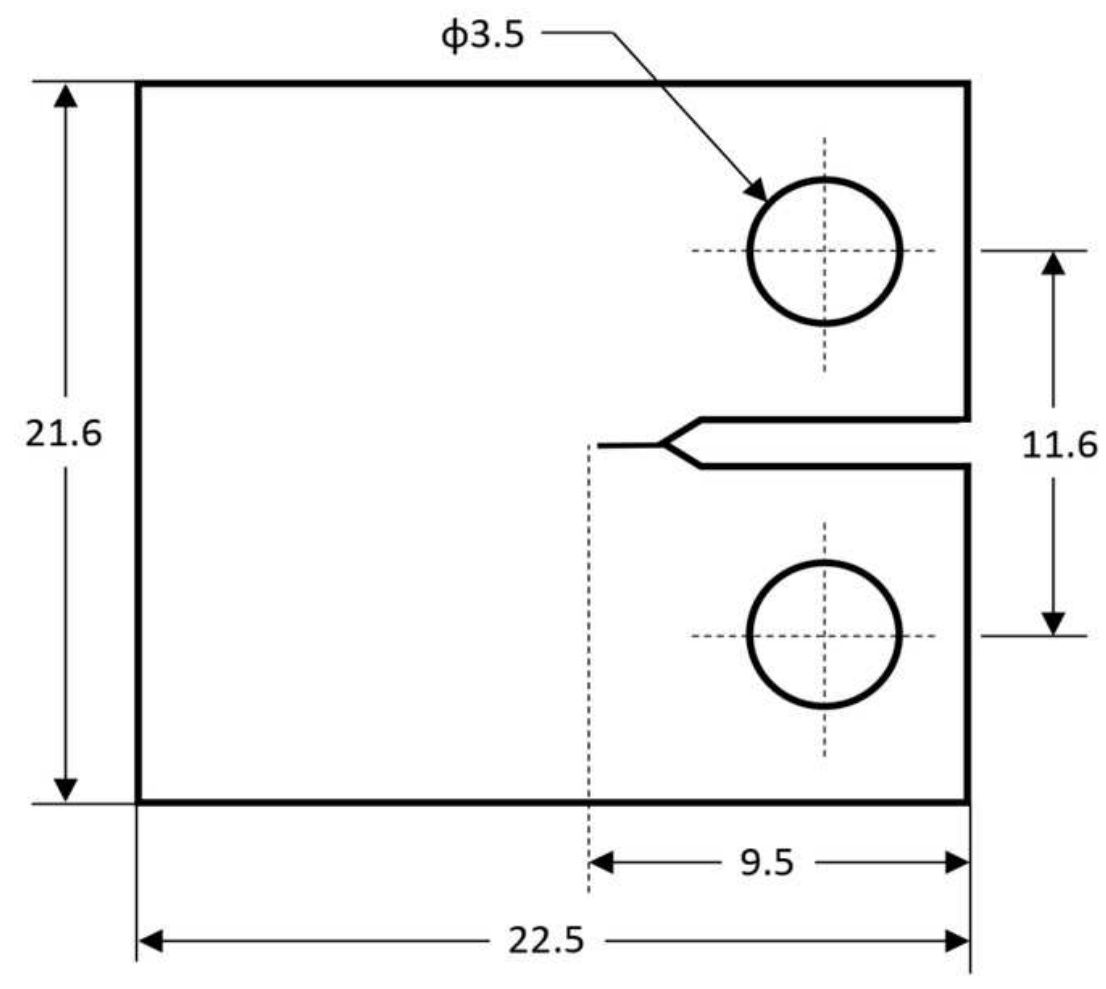

(b)

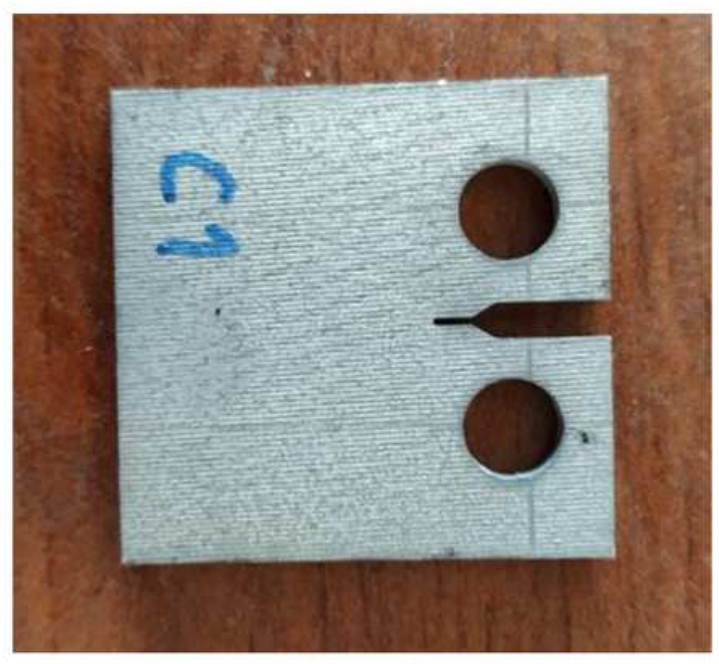

\section{Figure 2}

(a) Dimensions of CT sample according to ASTM E561 standard (all dimensions in $\mathrm{mm}$ ) and (b) one sample made by Wire-cut 


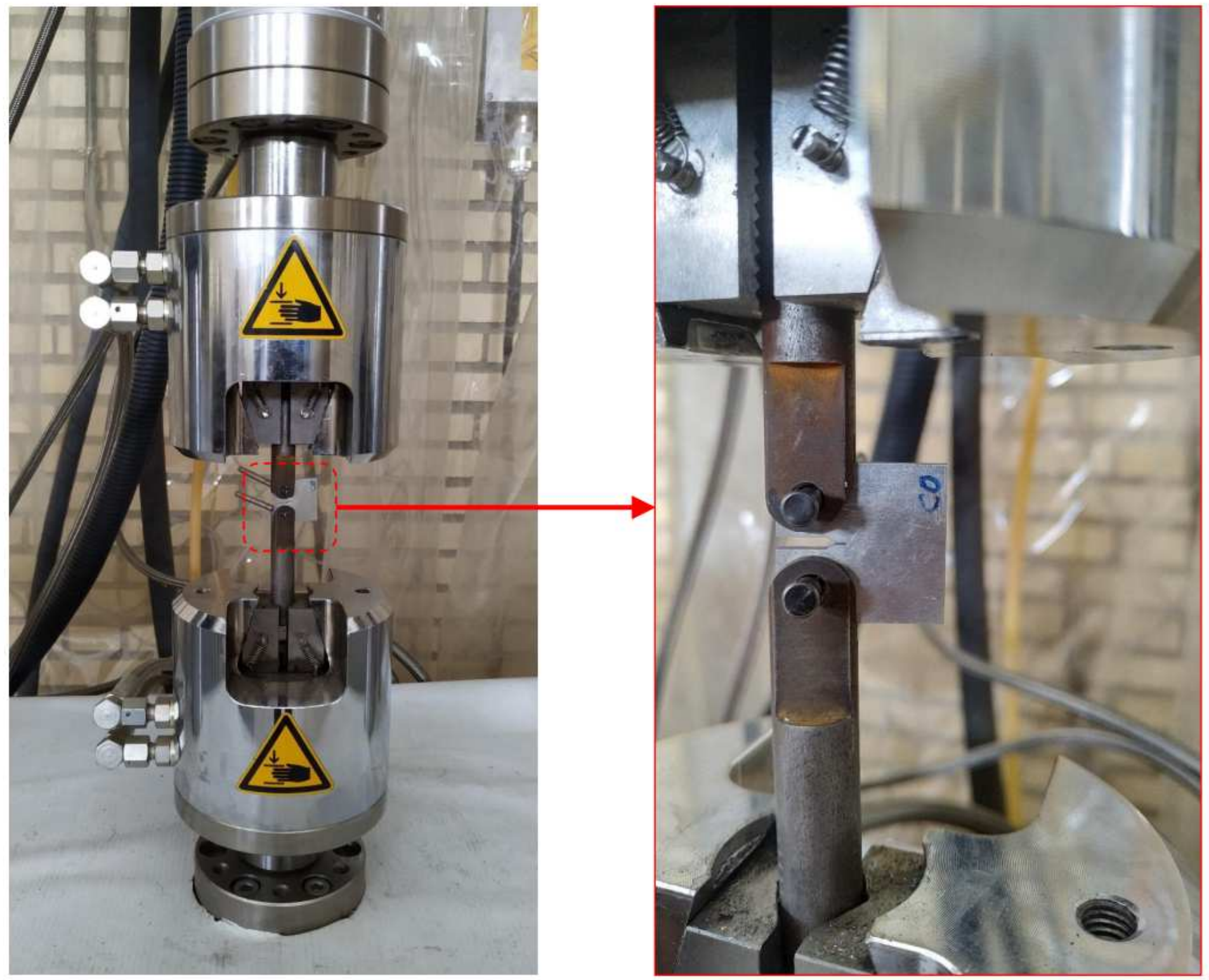

Figure 3

Experimental setup of the CT test in Zwick/Roell machine. 

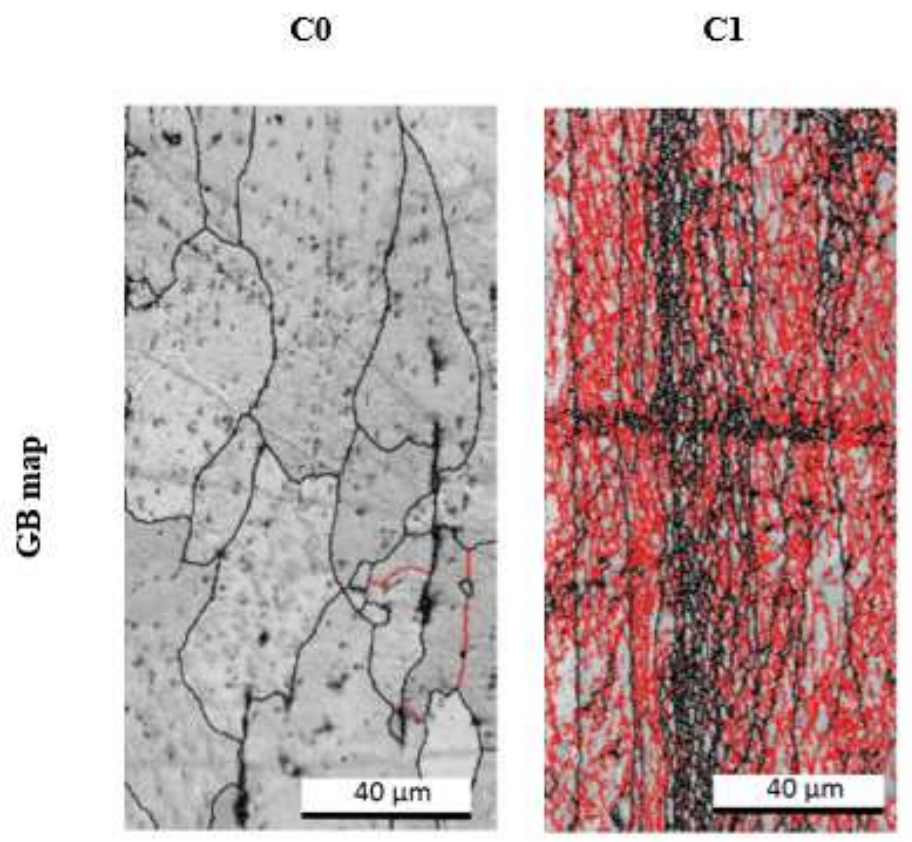

$\mathrm{C} 3$

C5
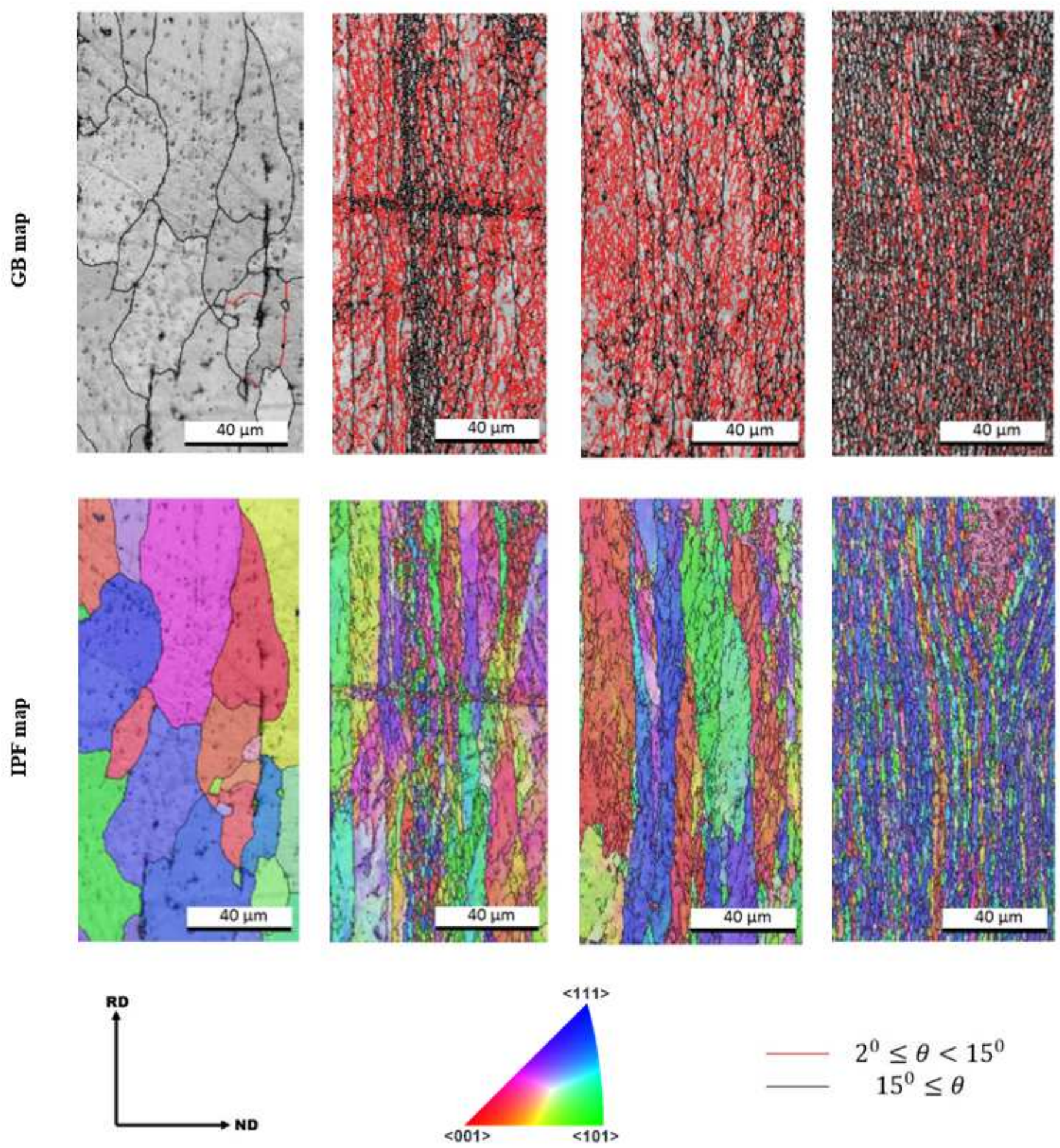

Figure 4

Boundary misorientation map (GB) and RD inverse pole figure maps (IPF map) of WARB-ed sheets after different cycles. 

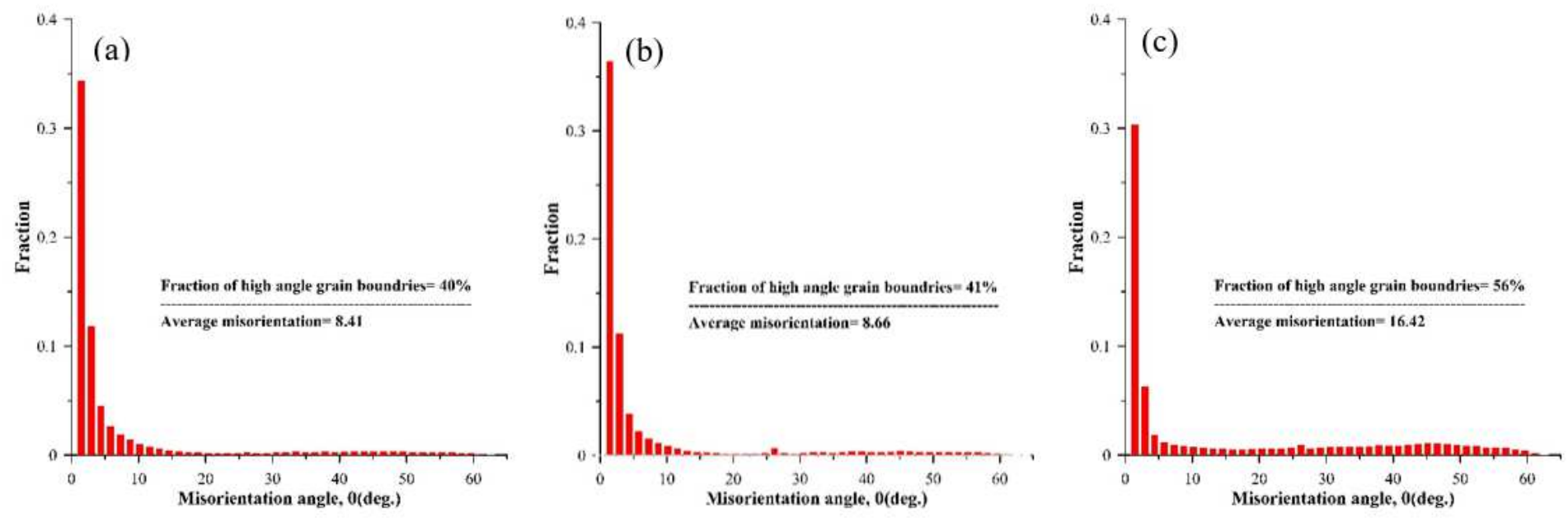

\section{Figure 5}

Histogram of misorientation angle distribution of WARB-processed AA1050 at (a) 1, (b) 3 and (c) 5 cycles.
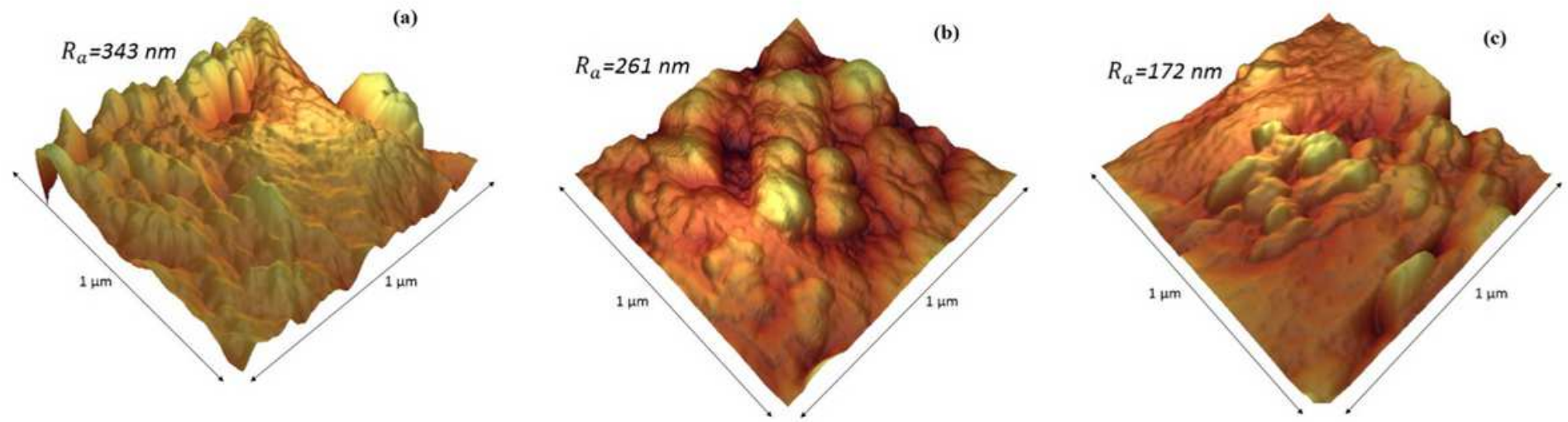

Figure 6

AFM images of the (a) C0, (b) C3 and (c) C5 specimens. 


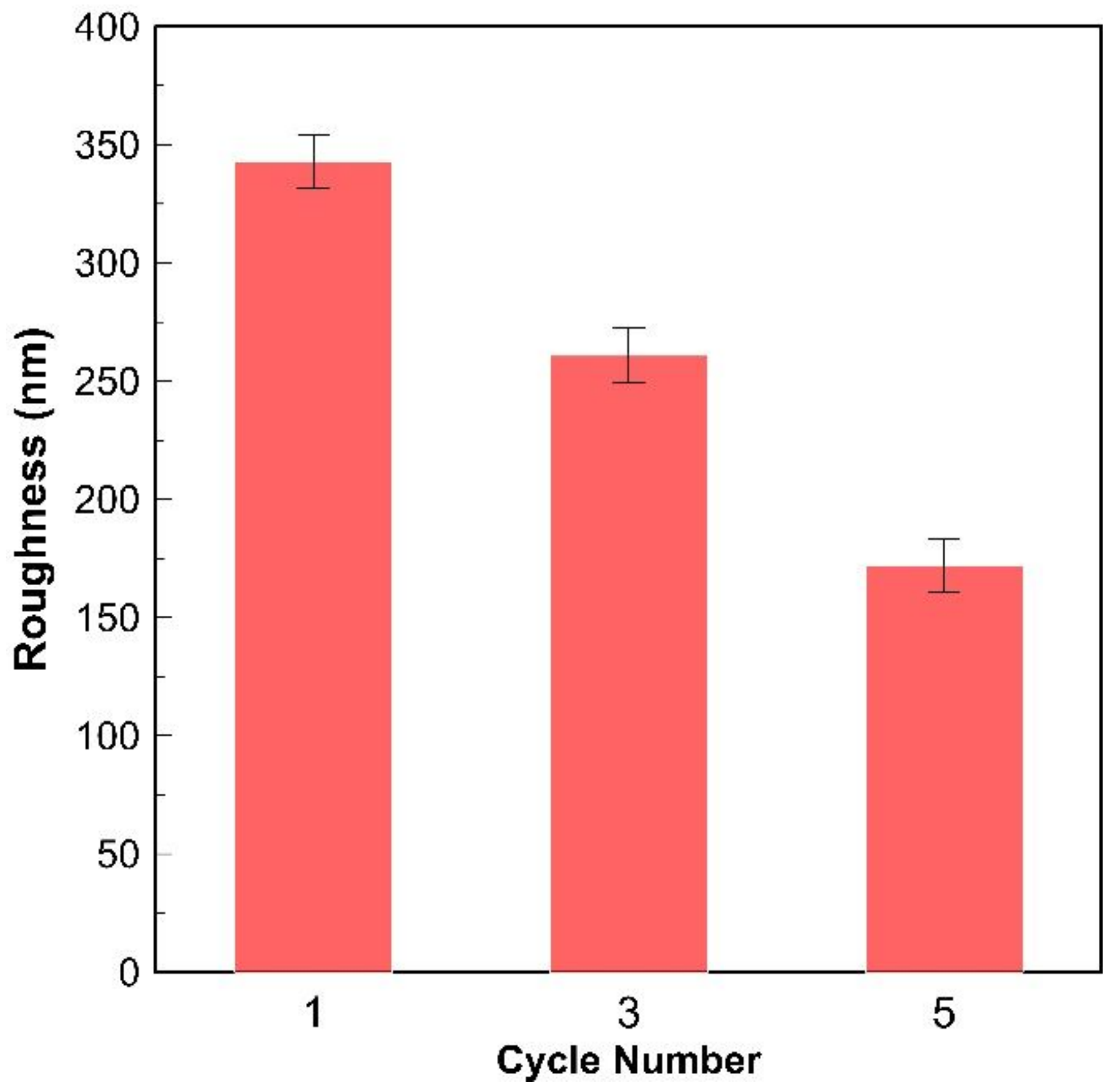

Figure 7

The variation of average surface roughness $(\mathrm{Ra})$ vs. WARB cycle. 


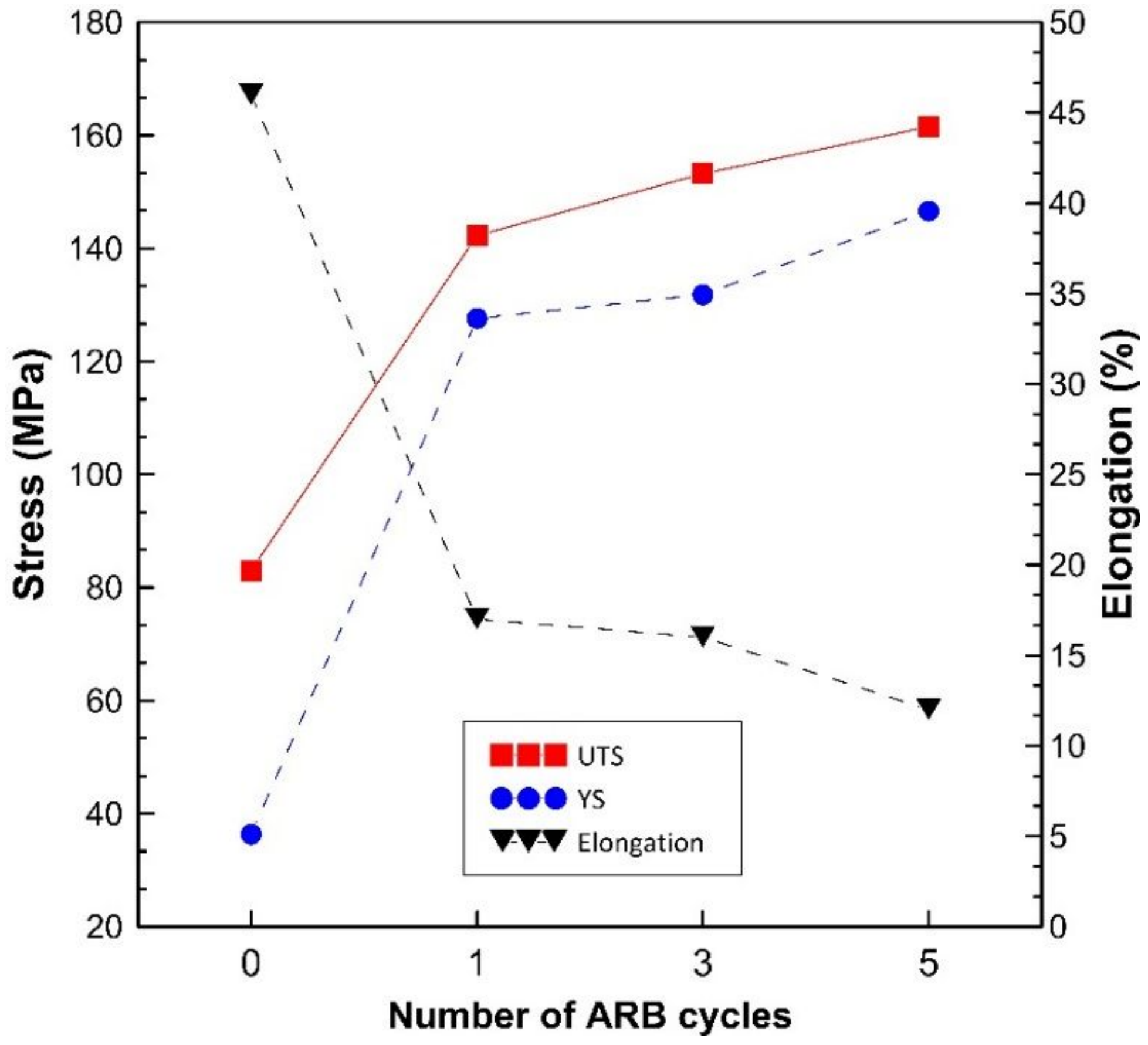

Figure 8

Changes in the mechanical characteristics with the number of WARB cycles ( 0 cycle represent asannealed state). 


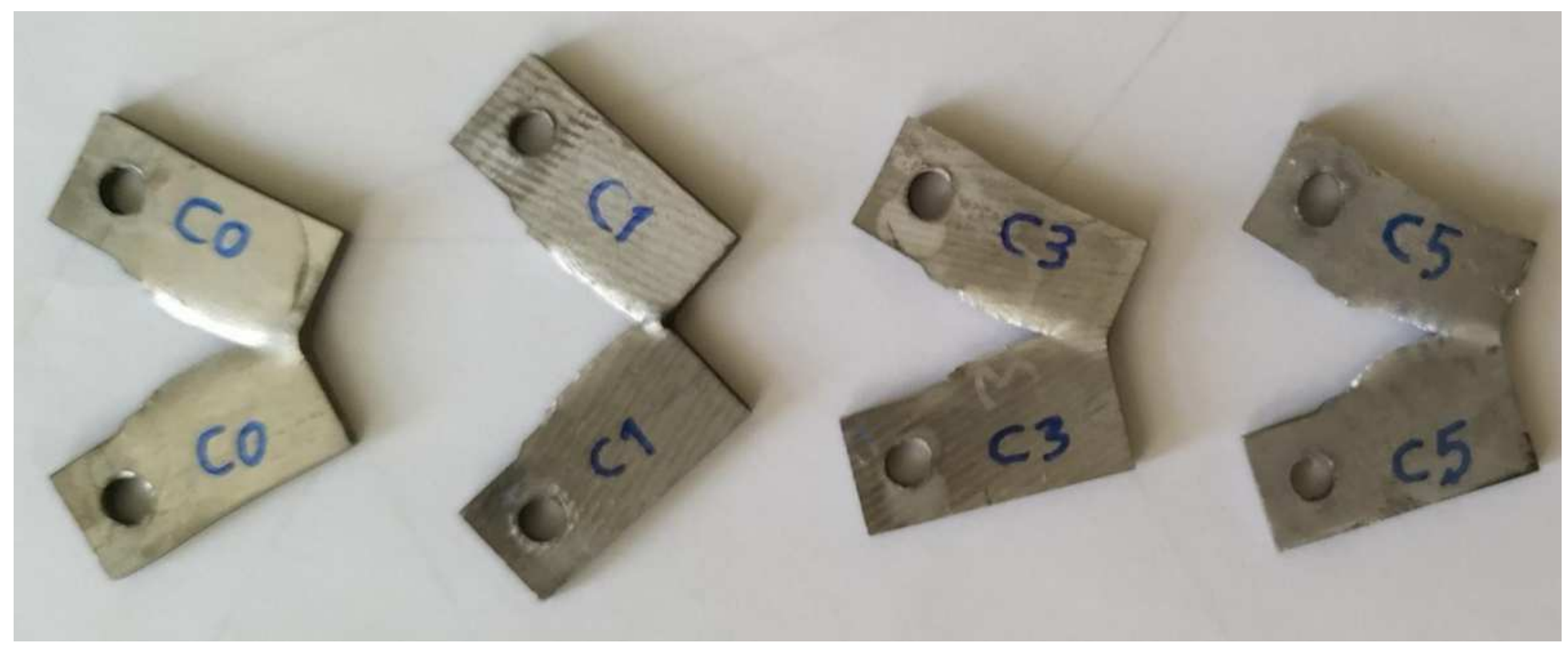

Figure 9

Some of the fractured CT specimens (CO, C1, C3 and C5 corresponds to annealed and WARB-ed samples at 1,3 and 5 cycles, respectively). 


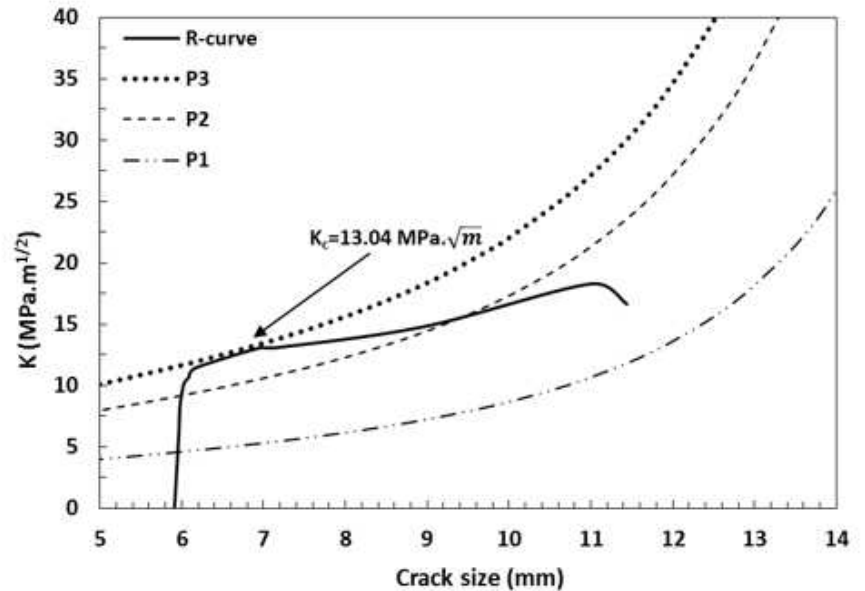

(a)

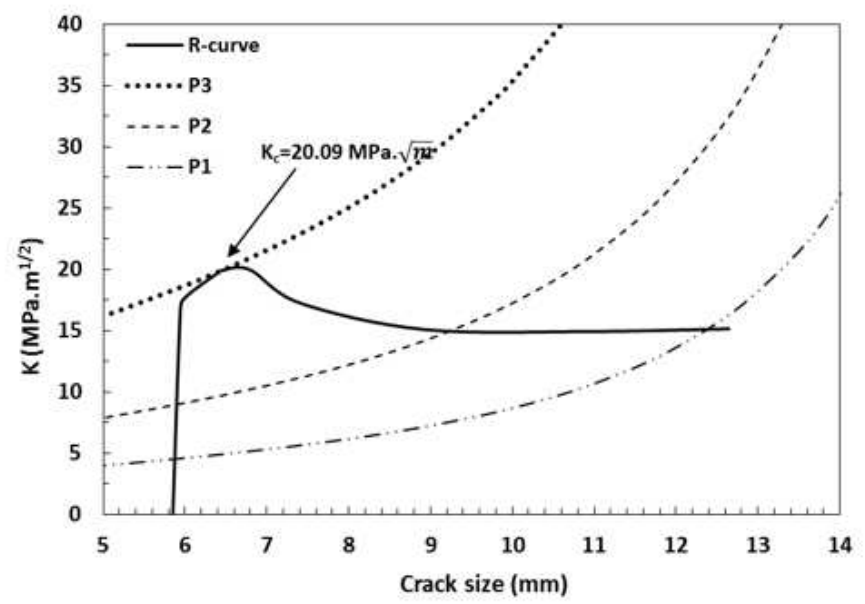

(c)

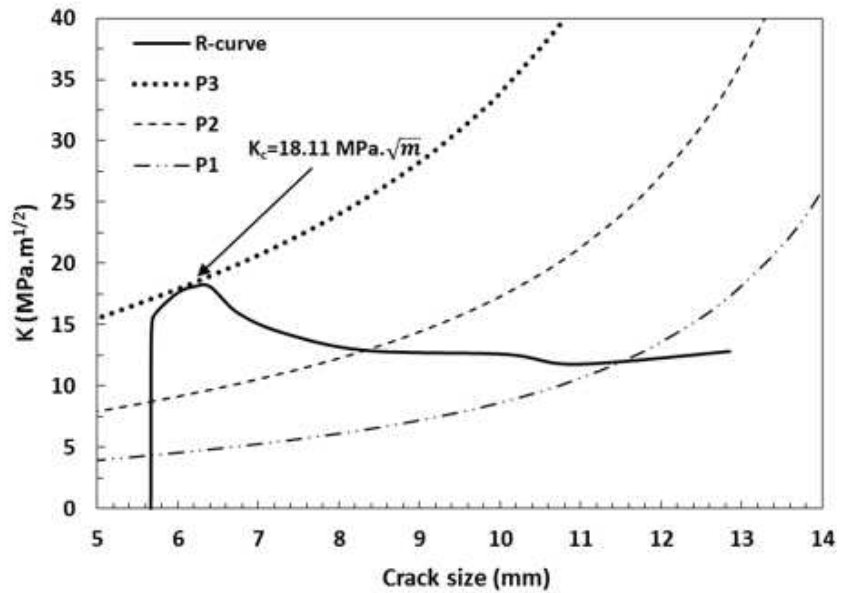

(b)

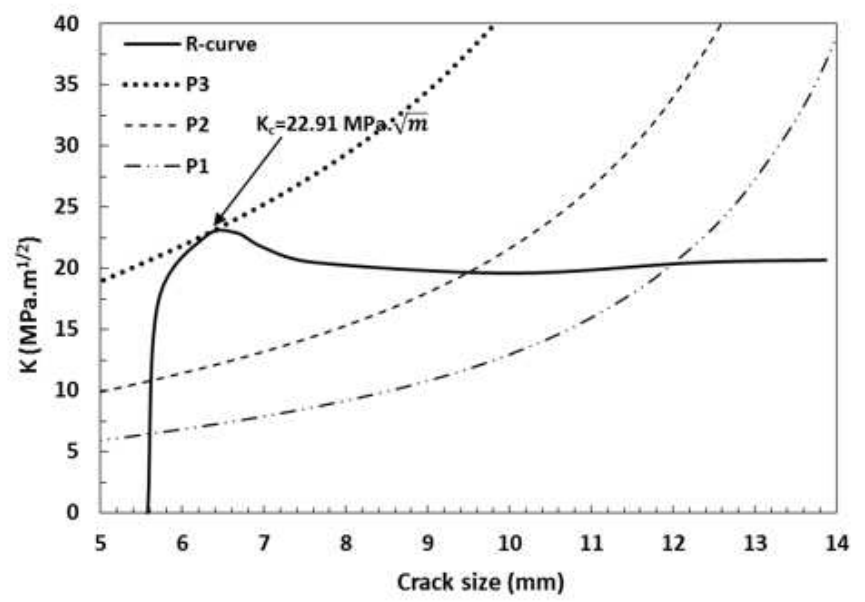

(d)

\section{Figure 10}

R-curves for AA1050 processed by WARB at (a) 0, (b) 1, (c) 3 and (d) 5 cycles ( 0 cycle represent asannealed state). 


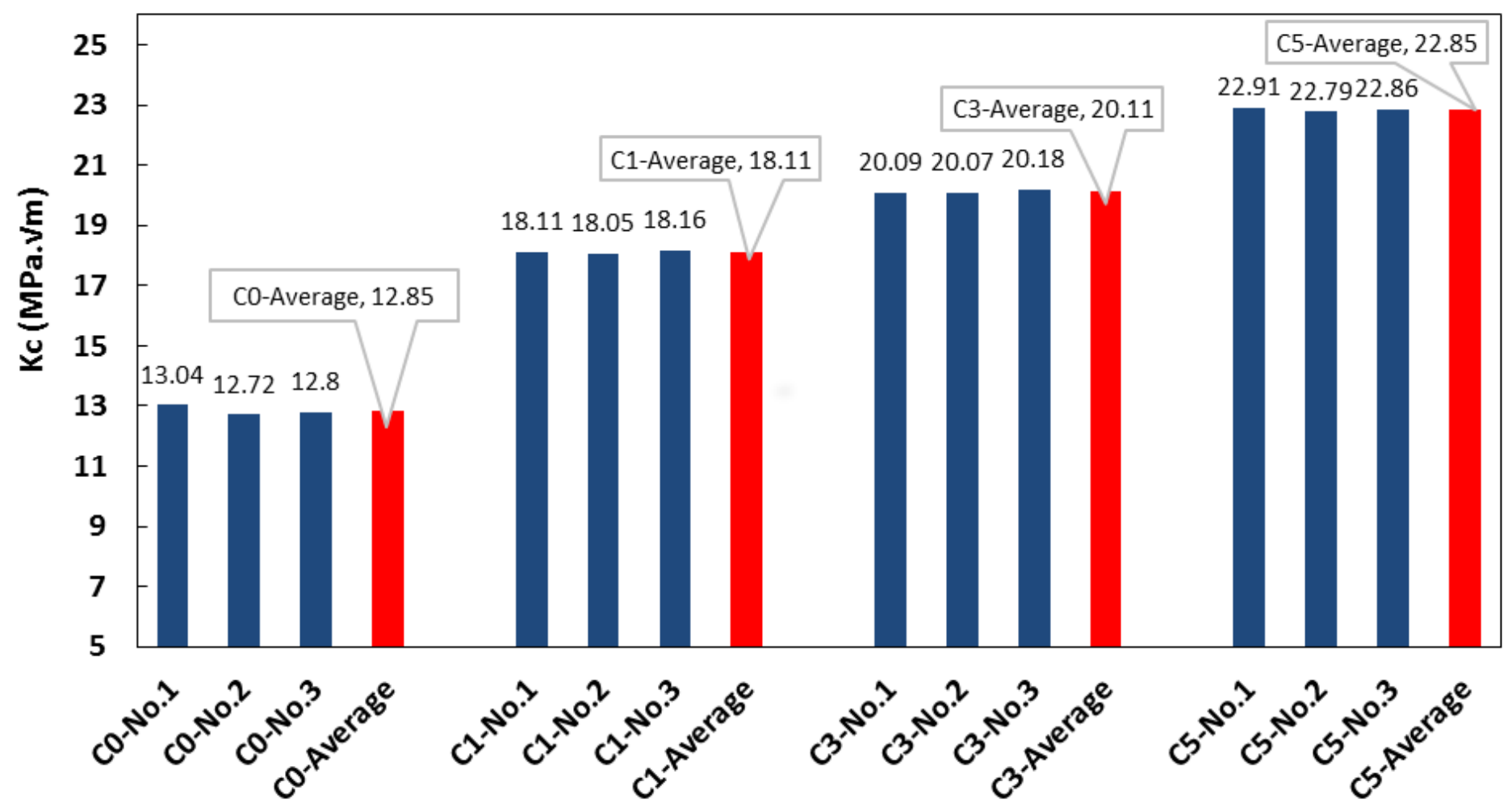

Figure 11

Fracture toughness variations in different cycles of the WARB process $(\mathrm{C} 0, \mathrm{C} 1, \mathrm{C} 3$ and $\mathrm{C} 5$ corresponds to annealed and WARB-ed samples at 1, 3 and 5 cycles, respectively).

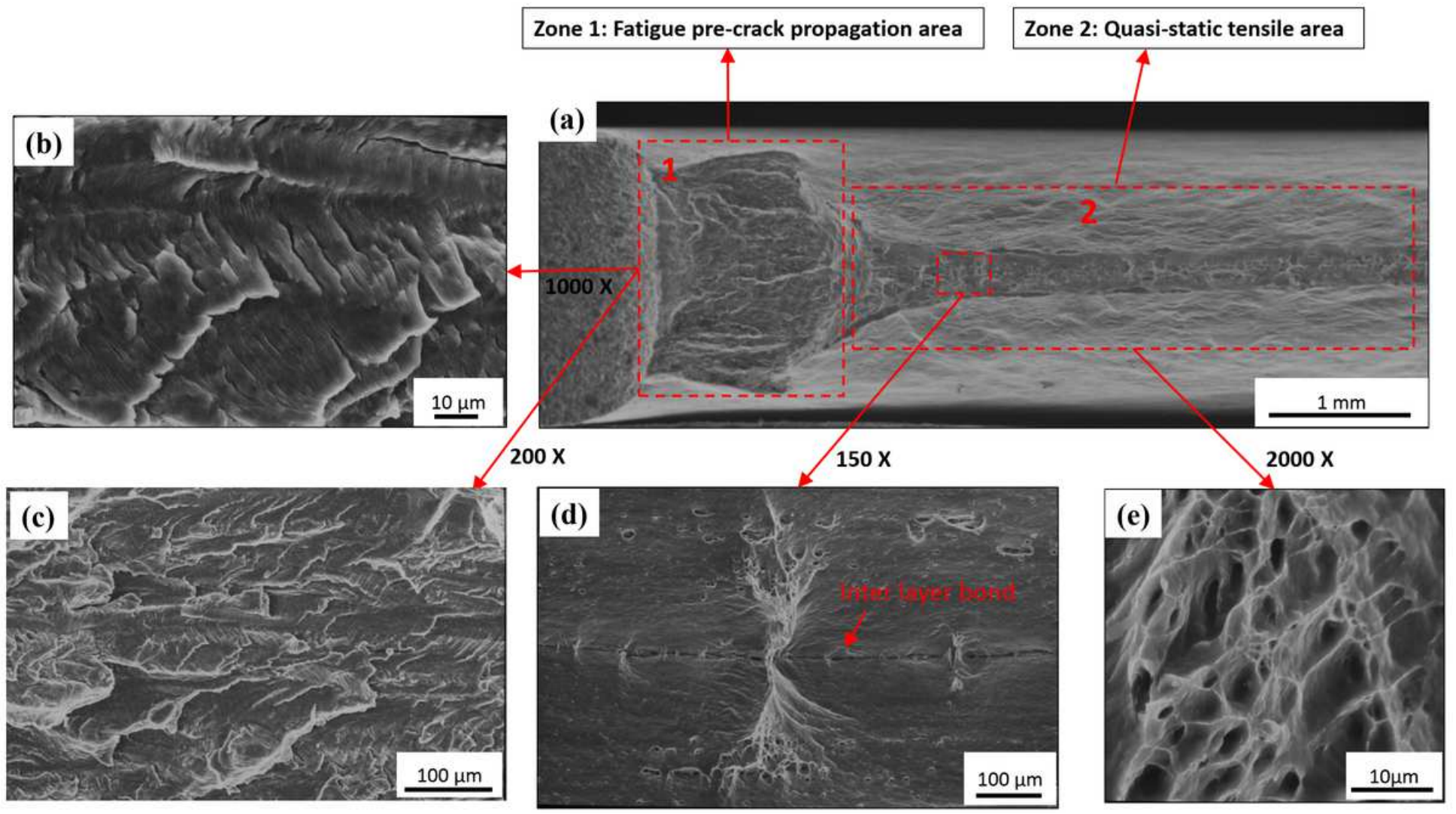


Figure 12

A comprehensive view of the CT specimen fracture surface after 1 cycle WARB.

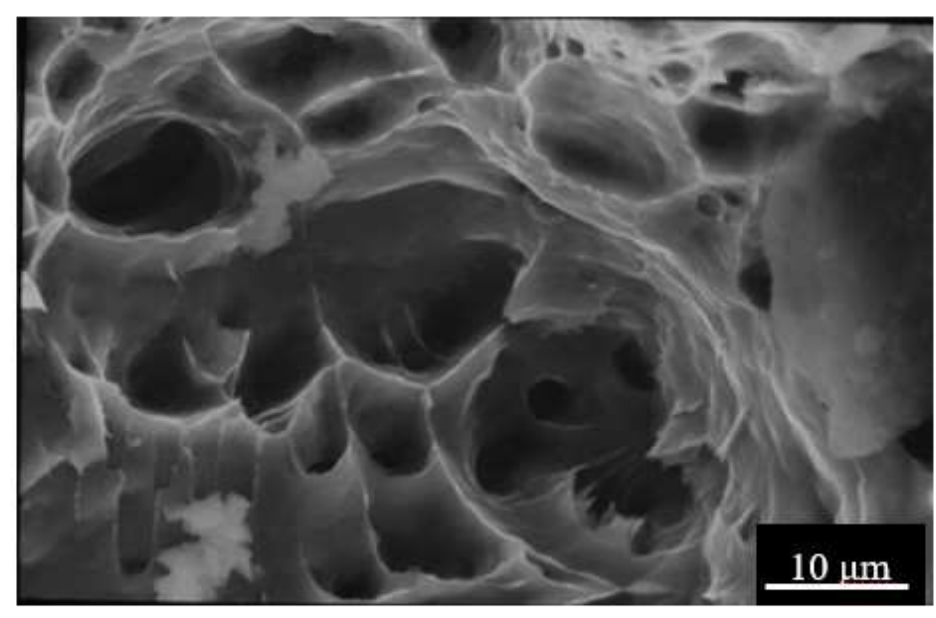

(a)

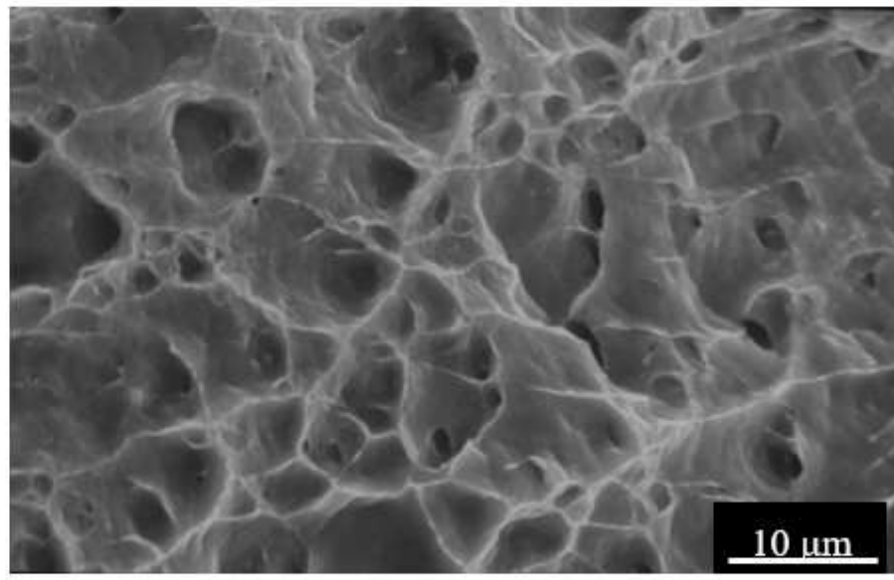

(c)

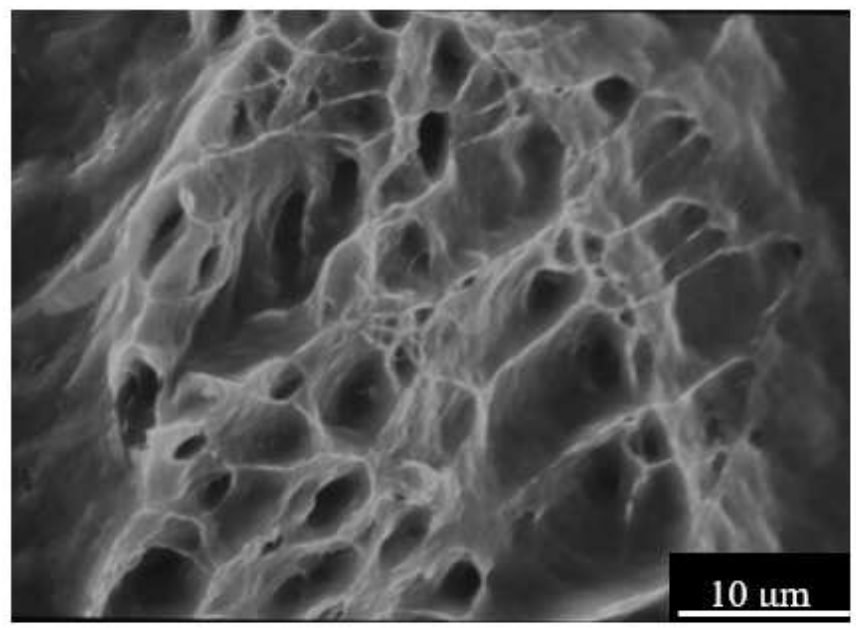

(b)

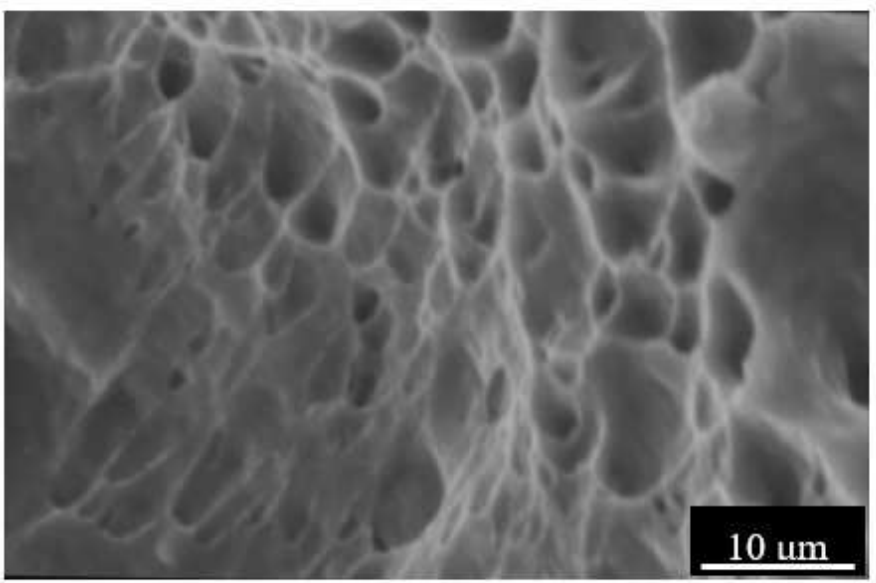

(d)

\section{Figure 13}

High magnification of CT specimen fractured surface after (a) annealing, (b) 1, (c) 3 and (d) 5 cycles WARB process. 